\title{
Review and uncertainty assessment of size-resolved scavenging coefficient formulations for below-cloud snow scavenging of atmospheric aerosols
}

\author{
L. Zhang ${ }^{1}$, X. Wang ${ }^{2}$, M. D. Moran ${ }^{1}$, and J. Feng ${ }^{3}$ \\ ${ }^{1}$ Air Quality Research Division, Science and Technology Branch, Environment Canada, 4905 Dufferin St, \\ Toronto, Ontario, M3H 5T4, Canada \\ ${ }^{2}$ Kellys Environmental Services, Toronto, Ontario, Canada \\ ${ }^{3}$ Canadian Meteorological Centre, Meteorological Service of Canada, Environment Canada, 2121 Trans-Canada Highway, \\ Dorval, Quebec, H9P 1J3, Canada
}

Correspondence to: L. Zhang (leiming.zhang@ec.gc.ca)

Received: 3 April 2013 - Published in Atmos. Chem. Phys. Discuss.: 5 June 2013

Revised: 10 September 2013 - Accepted: 19 September 2013 - Published: 11 October 2013

\begin{abstract}
Theoretical parameterizations for the sizeresolved scavenging coefficient for atmospheric aerosol particles scavenged by snow $\left(\Lambda_{\text {snow }}\right)$ need assumptions regarding (i) snow particle-aerosol particle collection efficiency $E$, (ii) snow-particle size distribution $N\left(D_{\mathrm{p}}\right)$, (iii) snow-particle terminal velocity $V_{D}$, and (iv) snow-particle cross-sectional area $A$. Existing formulas for these parameters are reviewed in the present study, and uncertainties in $\Lambda_{\text {snow }}$ caused by various combinations of these parameters are assessed. Different formulations of $E$ can cause uncertainties in $\Lambda_{\text {snow }}$ of more than one order of magnitude for all aerosol sizes for typical snowfall intensities. $E$ is the largest source of uncertainty among all the input parameters, similar to rain scavenging of atmospheric aerosols $\left(\Lambda_{\text {rain }}\right)$ as was found in a previous study by Wang et al. (2010). However, other parameters can also cause significant uncertainties in $\Lambda_{\text {snow }}$, and the uncertainties from these parameters are much larger than for $\Lambda_{\text {rain }}$. Specifically, different $N\left(D_{\mathrm{p}}\right)$ formulations can cause one-order-of-magnitude uncertainties in $\Lambda_{\text {snow }}$ for all aerosol sizes, as is also the case for a combination of uncertainties from both $V_{D}$ and $A$. Assumptions about dominant snowparticle shape (and thus different $V_{D}$ and $A$ ) will cause an uncertainty of up to one order of magnitude in the calculated scavenging coefficient. In comparison, uncertainties in $\Lambda_{\text {rain }}$ from $N\left(D_{\mathrm{p}}\right)$ are smaller than a factor of 5 , and those from $V_{D}$ are smaller than a factor of 2 . As expected, $\Lambda_{\text {snow }}$ estimated from empirical formulas generated from field measurements
\end{abstract}

falls in the upper range of, or is higher than, the theoretically estimated values, which can be explained by additional processes/mechanisms that influence field-derived $\Lambda_{\text {snow }}$ but that are not considered in the theoretical $\Lambda_{\text {snow }}$ formulas. Predicted aerosol concentrations obtained by using upper range vs. lower range of $\Lambda_{\text {snow }}$ values (a difference of around two orders of magnitude in $\Lambda_{\text {snow }}$ ) can differ by a factor of 2 for just a one-centimetre snowfall (liquid water equivalent of approximately $1 \mathrm{~mm}$ ). Based on the median and upper range of theoretically generated $\Lambda_{\text {snow }}$ and $\Lambda_{\text {snow }}$ values, it is likely that, for typical rain and snow events, the removal of atmospheric aerosol particles by snow is more effective than removal by rain for equivalent precipitation amounts, although a firm conclusion requires much more evidence.

\section{Introduction}

Many physical and chemical processes in chemical transport models (CTMs) need to be parameterized due to limitations in computer resources and our incomplete knowledge of these processes. For the scavenging and the removal of atmospheric aerosol particles by falling hydrometeors, the scavenging coefficient $\Lambda\left(\mathrm{s}^{-1}\right)$, which denotes the fraction of aerosol particles removed per unit time, is typically used when solving aerosol-particle mass continuity equations in CTMs (e.g. Baklanov and Sørensen, 2001; Loosmore and 
Cederwall, 2004; Gong et al., 2006; Henzing et al., 2006; Sofiev et al., 2006; Tost et al., 2006; Feng, 2007; Croft et al., 2009). Many laboratory, field, and theoretical studies have been conducted to quantify $\Lambda$ under rain and snow conditions (Martin et al., 1980; Slinn, 1984; Murakami et al., 1985; Miller and Wang, 1989; Dick, 1990; Maryon et al., 1992; Sparmacher et al., 1993; Bell and Saunders, 1995; Jylhä, 2000; Rotstayn and Lohmann, 2002; Laakso et al., 2003; Zhang et al., 2004; Chate, 2005; Andronache et al., 2006; Croft et al., 2009; Feng, 2009; Kyrö et al., 2009; Paramonov et al., 2011; Wang et al., 2011). However, large uncertainties still exist in current $\Lambda$ parameterizations due to the many factors involved in the scavenging processes.

An assessment of uncertainties in size-resolved $\Lambda$ for aerosols scavenged by rain $\left(\Lambda_{\text {rain }}\right)$ was recently conducted by Wang et al. (2010). The present study follows a similar approach to assessing uncertainties of size-resolved $\Lambda$ for aerosols scavenged by snow $\left(\Lambda_{\text {snow }}\right)$. Such a study is needed given that current knowledge of snow scavenging is considerably more limited than that for rain scavenging. One reason is that scavenging by snow is more complicated due to the wide variety of snow-particle shapes, sizes, and densities, which results in different fall speeds, cross-sectional areas, and flow patterns around snow particles (Pruppacher and Klett, 1997; Jylhä, 1999). On the other hand, snow scavenging is an important removal mechanism in mid-latitude and polar regions in the winter and in mountainous areas and in the upper troposphere at all times of year. One study estimated that roughly $30 \%$ of below-cloud scavenging of sulfate particles by precipitation is due to snow (Croft et al., 2009).

Current treatments of snow scavenging of atmospheric aerosol particles in CTMs vary substantially, ranging from using a bulk $\Lambda$ parameterized as a function of snowfall intensity (as liquid water equivalent) without considering the sizes of either aerosol or snow particles (Baklanov and Sørensen, 2001; Sofiev et al., 2006) to using the same size-resolved $\Lambda$ formula as that for rain scavenging to using a size-resolved $\Lambda$ formula specifically developed for snow conditions (e.g. Gong et al., 2006; Croft et al., 2009; Feng, 2009). Past reviews have documented these various approaches (Rasch et al., 2000; Textor et al., 2006; Sportisse, 2007; Zhang, 2008; Gong et al., 2011). The present study, however, attempts to quantify the uncertainties related to various parameters chosen for the existing size-resolved $\Lambda_{\text {snow }}$ formulas developed specifically for snow conditions.

In the following sections, a brief overview of current sizeresolved $\Lambda_{\text {snow }}$ parameterizations, including their component parameters, is first given (Sect. 2); next, a summary of the results of sensitivity tests that were conducted to investigate uncertainties in $\Lambda_{\text {snow }}$ induced by these various parameters is provided (Sect. 3). The uncertainties of existing theoretical size-resolved $\Lambda_{\text {snow }}$ parameterizations are then assessed further by using various combinations of the component parameter formulas (Sect. 4.1) and by comparing with an avail- able empirical $\Lambda_{\text {snow }}$ parameterization derived directly from fits to field measurements (Sect. 4.2). The impact of different $\Lambda_{\text {snow }}$ formulas on predicted aerosol concentrations is then briefly discussed (Sect. 4.3), and a comparison of uncertainties between $\Lambda_{\text {snow }}$ and $\Lambda_{\text {rain }}$ is presented (Sect. 4.4). Lastly, some conclusions are given in Sect. 5 .

\section{Theory of size-resolved snow scavenging coefficient $\Lambda_{\text {snow }}$}

The terminology of ice or snow particles reflects the greater physical variability of frozen or solid hydrometeors vs. liquid hydrometeors (rain drops). As discussed by Pruppacher and Klett (1997), small ice particles that have grown only by water vapour diffusion are called snow crystals. These snow crystals have different shapes or habits, including plates, columns, stars, needles, dendrites, spheres, and bullets. Aggregates of snow crystals are called snowflakes. Individual snow crystals usually have a maximum dimension $D_{\mathrm{m}}$ of less than $5 \mathrm{~mm}$, whereas snowflakes may have a maximum dimension of several centimetres. Snow crystals can also grow by collisions with cloud drops, which is called riming. Depending upon the degree of riming, these snow particles may be referred to as rimed snow crystals or graupel particles or ice pellets. All of these rimed snow particles usually have $D_{\mathrm{m}}$ values of less than $5 \mathrm{~mm}$; heavily rimed, larger particles are called hailstones.

Typical regional- to global-scale CTMs, however, do not provide the information about snow crystal type and shape, but only about total solid precipitation flux, which can then be used for the scavenging calculations either with additional assumptions about snow crystal type or by using generalized crystal types/shapes. Such assumptions about snow crystal types and shapes, though, will introduce uncertainties in $\Lambda_{\text {snow }}$ not present in $\Lambda_{\text {rain }}$ since different snow crystal shapes have different physical properties (see below) that affect the scavenging process.

In CTMs that simulate aerosol-particle number concentrations, the below-cloud scavenging of aerosol particles by snow particles is commonly described as (Seinfeld and Pandis, 2006)

$\frac{\partial n\left(d_{\mathrm{p}}, t\right)}{\partial t}=-\Lambda_{\text {snow }}\left(d_{\mathrm{p}}\right) \cdot n\left(d_{\mathrm{p}}, t\right)$,

where $n\left(d_{\mathrm{p}}, t\right)$ is the number concentration of aerosol particles with diameter $d_{\mathrm{p}}$ at time $t$, and $\Lambda_{\text {snow }}\left(d_{\mathrm{p}}\right)$ is the scavenging coefficient for aerosol particles of size $d_{\mathrm{p}}$ and can be calculated based on the concept of collection efficiency between falling hydrometeors and aerosol particles (e.g. Slinn, 1984). The size-resolved scavenging coefficient is parameterized as

$\Lambda_{\text {snow }}\left(d_{\mathrm{p}}\right)=\int_{0}^{\infty} A\left(V_{D}-v_{d}\right) E\left(d_{\mathrm{p}}, D_{\mathrm{p}}\right) N\left(D_{\mathrm{p}}\right) d D_{\mathrm{p}}$, 
Table 1. List of semi-empirical formulas for $E\left(d_{\mathrm{p}}, D_{\mathrm{p}}\right)$.

\begin{tabular}{|c|c|}
\hline Source & Formulas \\
\hline Slinn $(1984)^{\mathrm{a}}$ & $E\left(d_{\mathrm{p}}, \lambda\right)=\left(\frac{1}{S c}\right)^{\alpha}+\left[1-\exp \left(-\left(1+R e_{\lambda}^{1 / 2}\right)\right) \frac{\left(d_{\mathrm{p}} / 2\right)^{2}}{\lambda^{2}}\right]+\left(\frac{S t-S t^{*}}{S t-S t^{*}+2 / 3}\right)^{3 / 2}$ \\
\hline Murakami et al. $(1985)^{\mathrm{b}}$ & $E\left(d_{\mathrm{p}}, D_{\mathrm{m}}\right)=\frac{48 D_{\mathrm{diff}}}{\pi D_{\mathrm{m}} V_{D}}\left(0.65+0.44 S c^{1 / 3} R e^{1 / 2}\right)+28.5 I^{1.186}+\left(\frac{S_{1}-S_{2}}{S_{2} \exp \left(S_{1} t^{\prime}\right)-S_{1} \exp \left(S_{2} t^{\prime}\right)}\right)^{2}$ \\
\hline $\operatorname{Dick}(1990)^{\mathrm{c}}$ & $E\left(d_{\mathrm{p}}, D_{\mathrm{m}}\right)=\frac{4}{P e}\left(1+0.4 R e^{1 / 6} P e^{1 / 3}\right)+\frac{2 m V_{D}}{3 \pi d_{\mathrm{p}} \mu_{\mathrm{a}} D_{\mathrm{m}}}$ \\
\hline \multicolumn{2}{|c|}{$\begin{array}{l}\lambda \text { is the characteristic capture length and depends on the shape of snow particles (e.g. sleet/graupel, rimed crystals, powder snow, dendrite, tissue paper, and } \\
\text { camera film). Re } e_{\lambda} \text { is the Reynolds number corresponding to the specific } \lambda . S c \text { is the Schmidt number: } S c=\mu_{\mathrm{a}} / \rho_{\mathrm{a}} D_{\text {diff }} \text {, where } \mu_{\mathrm{a}} \text { is the dynamic air viscosity, } \\
\rho_{\mathrm{a}} \text { is the air density and } D_{\text {diff }} \text { is the aerosol-particle diffusion coefficient. } S t \text { is the Stokes number and } S t^{*} \text { is the critical Stokes number: } \\
S t^{*}=\frac{1.2+(1 / 12) \ln (1+R e}{}\left(1+\ln \left(1+R e_{\lambda}\right)\right.\end{array}$} \\
\hline \multicolumn{2}{|c|}{$\begin{array}{l}{ }^{\mathrm{b}} \text { The formula is for snow aggregates. } D_{\text {diff }} \text { is the aerosol-particle diffusion coefficient, } R e \text { is the Reynolds number of a snow particle: } R e=D_{\mathrm{m}} V_{D} \rho_{\mathrm{a}} / \mu_{\mathrm{a}} \text {, } \\
\text { where } \rho_{\mathrm{a}} \text { is the air density and } \mu_{\mathrm{a}} \text { is the dynamic air viscosity. } S c \text { is the Schmidt number: } S c=\mu_{\mathrm{a}} / \rho_{\mathrm{a}} D_{\text {diff }} \text {, and } I \text { is the size ratio } d_{\mathrm{p}} / D_{\mathrm{c}} \text {, with } D_{\mathrm{c}} \text { the } \\
\text { characteristic length of the snow particle. The third term is the theoretical solution of a simplified flow model by Ranz and Wong }(1952) \text {, involving parameters }\end{array}$} \\
\hline$S_{1}, S_{2}$ and $t^{\prime}$, and can be simplifiec & to $\exp \left(\frac{-0.11}{S t^{1 / 2}-0.25}\right)$ if $S t \geq 1 / 16$, or to 0 if $S t<1 / 16$ (Feng, 2009), where $S t$ is the Stokes number. \\
\hline
\end{tabular}

where $N\left(D_{\mathrm{p}}\right) d D_{\mathrm{p}}$ is the number of snow particles with a melted diameter between $D_{\mathrm{p}}$ and $D_{\mathrm{p}}+d D_{\mathrm{p}}$ in a unit volume of air $\left(\mathrm{m}^{-3}\right), V_{D}$ and $v_{d}$ are the terminal velocities $\left(\mathrm{m} \mathrm{s}^{-1}\right)$ of snow particles and aerosol particles, respectively, $E\left(d_{\mathrm{p}}, D_{\mathrm{p}}\right)$ is the collection efficiency (dimensionless) between aerosol particles of size $d_{\mathrm{p}}$ and a snow particle of melted size $D_{\mathrm{p}}$, and $A$ is the effective cross-sectional area of a snow-particle projected normal to the fall direction $\left(\mathrm{m}^{2}\right)$. According to Eq. (2), four parameters thus determine the value of $\Lambda_{\text {snow }}\left(d_{\mathrm{p}}\right)$ : (i) the snow particle-aerosol particle collection efficiency; (ii) the snow-particle number size distribution; (iii) the snow-particle terminal velocity (assuming $V_{D} \gg v_{d}$ ); and (iv) the snowparticle effective cross-sectional area. Available formulas for these four parameters are reviewed and discussed below. All symbols used in this study are defined in Table A1.

\subsection{Snow particle-aerosol particle collection efficiency $E\left(d_{\mathrm{p}}, D_{\mathrm{p}}\right)$}

$E\left(d_{\mathrm{p}}, D_{\mathrm{p}}\right)$, the collection efficiency for aerosol particles of diameter $d_{\mathrm{p}}$ of a snow particle of melted diameter $D_{\mathrm{p}}$, gives the rate of collection of aerosol particles of diameter $d_{\mathrm{p}}$ by the falling snow particle normalized by the number of upstream aerosol particles of diameter $d_{\mathrm{p}}$ swept per unit time across an area equal to the effective cross-sectional area of the snow particle (e.g. Slinn, 1984). The collection efficiency is the most important parameter in the calculation of the scavenging coefficient $\Lambda_{\text {snow }}$ in Eq. (2). There are considerably fewer studies on $E$ for snow particles and aerosol particles than there are for rain drops and aerosol particles. However, there are a few studies that describe $E$ based on rigorous theoretical models involving (i) a particle trajectory model under the influence of the flow field of falling snow crystals and (ii) a convective diffusion model for small aerosol particles. For example, Martin et al. (1980) studied $E$ for planar snow crys- tals (approximated as hexagonal plates) at low to intermediate Reynolds numbers, and Miller and Wang (1989) studied $E$ for columnar snow crystals using a theoretical model. Several field measurements and laboratory experiments under controlled conditions have also been conducted to study and verify theoretical results (e.g. Knutson et al., 1976; Sauter and Wang, 1989; Murakami et al., 1985). These studies suggest that a complete theoretical model for $E$ would be too complex to be implemented in CTMs.

Three different size-resolved semi-empirical formulas for $E$ have been developed for snow scavenging for CTM applications (Slinn, 1984; Murakami et al., 1985; Dick, 1990) as listed in Table 1. Generally these formulas use a conceptual model that a hydrometeor can collide with an aerosol particle through the mechanisms of Brownian diffusion, interception, and impaction. Both the formulas of Slinn (1984) and Murakami et al. (1985) consist of three terms, representing the contributions from these three mechanisms respectively. Dick's formula has only two terms, considering the contributions from Brownian diffusion and impaction but neglecting interception. All three formulas parameterize the contribution from impaction using the Stokes number. The contribution from collisions due to Brownian diffusion is parameterized using the Schmidt number by Slinn, the Schmidt number and the Reynolds number by Murakami et al. (1985), and the Reynolds number and the Péclet number by Dick. Slinn's formula parameterizes the contribution due to interception through the Reynolds number and the interception parameter (defined as $d_{\mathrm{p}} / \lambda$, where $\lambda$ is the characteristic length of the snow particle), whereas Murakami et al. (1985) only use the interception parameter and parameterize it using a simple power-law relationship. Some of these formulas for $E$ have been used to parameterize $\Lambda_{\text {snow }}$ in current CTMs (e.g. Gong et al., 2006; Croft et al., 2009; Feng, 2009). 
Table 2. List of exponential snow-particle number size distributions. Actual snow-particle size was used in Scott (1982) (see Appendix A), whereas melted snow-particle sizes were used in other formulas. $R$ is precipitation intensity $\left(\mathrm{mm} \mathrm{h}^{-1}\right)$, and $M$ is precipitation water concentration $\left(\mathrm{g} \mathrm{m}^{-3}\right)$.

\begin{tabular}{lll}
\hline & $N\left(D_{\mathrm{p}}\right)=N_{0 \mathrm{e}} \exp \left(-\beta_{\mathrm{e}} D_{\mathrm{p}}\right)$ \\
\hline Source & $N_{0 \mathrm{e}}\left[\mathrm{cm}^{-4}\right]$ & $\beta_{\mathrm{e}}\left[\mathrm{cm}^{-1}\right]$ \\
\hline Marshall and Palmer (1948) & 0.08 & $\beta_{\mathrm{e}}=41 R^{-0.21}$ \\
\hline Scott (1982) & 0.5 & $M=0.37 R^{0.94}$ \\
& & $\beta_{\mathrm{e}}=20.7 M^{-0.33}=28.8 R^{-0.31}$ \\
\hline Gunn and Marshall (1958) & $N_{0 \mathrm{e}}=0.038 R^{-0.87}$ & $\beta_{\mathrm{e}}=25.5 R^{-0.48}$ \\
\hline Sekhon and Srivastava (1970) & $N_{0 \mathrm{e}}=0.025 R^{-0.94}$ & $\beta_{\mathrm{e}}=22.9 R^{-0.45}$ \\
\hline
\end{tabular}

\subsection{Snow-particle number size distribution $N\left(D_{\mathrm{p}}\right)$}

$\Lambda_{\text {snow }}$ also depends on the number size spectrum of snow particles. Various microphysical and dynamical processes inside and below cloud layers modify snow-particle size spectra. Other factors affecting snow-particle size spectra include ambient temperature, particle habit, precipitation intensity, and the stage of cloud and precipitation development (e.g. Harimaya et al., 2004; Woods et al., 2008). In practical applications, empirical mathematical formulas derived from the observed size spectra have been used to approximate natural snow-particle size distributions (e.g. Marshall and Palmer, 1948; Gunn and Marshall, 1958; Sekhon and Srivastava, 1970; Scott, 1982; Smith, 1984; Mitchell, 1991; Heymsfield, 2003; Field et al., 2005; Woods et al., 2008). For example, the exponential Marshall-Palmer size distribution (Marshall and Palmer, 1948), originally proposed for raindrop size distribution, was also found to describe snow-particle size distribution reasonably well (Passarelli, 1978). Gunn and Marshall (1958) reported another exponential size distribution function for aggregate snowflakes, the first one to be derived directly from ground observations of snow, following an assessment method similar to that used for raindrop size distributions by Marshall and Palmer (1948). By reanalysing the data set of Gunn and Marshall (1958) as well as analysing additional snowflake size distribution measurements, Sekhon and Srivastava (1970) suggested an updated exponential formula. Scott (1982) modified the parameters in the MarshallPalmer distribution based on results from Passarelli (1978) and Houze Jr. et al. (1979), so the modified exponential function can be applied to large spatial scales. To date, exponential distributions have been widely used in various cloud microphysics to represent snow size spectra (e.g. Cotton et al., 1982; Lin et al., 1983; Rutledge and Hobbs, 1983; Reisner et al., 1998; Thompson et al., 2004; Croft et al., 2009; Feng, 2009; Solomon et al., 2009).

The basic form of the exponential function for snowparticle number size distribution is written as

$N\left(D_{\mathrm{p}}\right)=N_{0 \mathrm{e}} \exp \left(-\beta_{\mathrm{e}} D_{\mathrm{p}}\right)$, where $N_{0 \mathrm{e}}$ is the intercept parameter and $\beta_{\mathrm{e}}$ is a slope parameter. Different researchers, however, have treated $N_{0 \mathrm{e}}$ and $\beta_{\mathrm{e}}$ in different ways: some have adopted a fixed $N_{0 \mathrm{e}}$, whereas others have varied $N_{0 \mathrm{e}}$ according to precipitation intensity (Table 2). Note that the parameters in Scott (1982) are based on actual snow-particle size $D_{\mathrm{m}}$, whereas the other three distributions listed in Table 2 are for equivalent drop sizes $D_{\mathrm{p}}$. A conversion of snow-particle size to equivalent melted drop size is needed for the Scott (1982) formula (see Appendix A) to allow a direct comparison of these distributions (see Sect. 3.2).

\subsection{Snow-particle terminal velocity $V_{D}$}

Terminal velocities for various snow-particle types have been studied both experimentally and theoretically, and corresponding empirical parameterizations have been developed (e.g. Langleben, 1954; Pruppacher and Klett, 1997; Mitchell, 1996; Mitchell and Heymsfield, 2005). Early formulas for snow-particle terminal velocity were derived directly from fall speed measurements (i.e. experimentally based) and treated the terminal velocity $V_{D}$ as a power-law function of the ice particle maximum dimension $D_{\mathrm{m}}: V_{D}=a_{v} D_{\mathrm{m}}^{b_{v}}$, where $a_{v}$ and $b_{v}$ are empirical constants but vary with snow crystal habit (e.g. Langleben, 1954; Starr and Cox, 1985). However, the application of most experimentally based empirical formulas is limited to the particle shape for which the measurements were conducted (see Table 3). More recently developed parameterizations are theoretically based formulas. A power-law relationship is first determined between the Reynolds number (Re; dimensionless) and the best or Davies number $\left(X=\frac{2 m g \rho_{\mathrm{a}} D_{\mathrm{m}}^{2}}{A \mu_{\mathrm{a}}^{2}} ;\right.$ dimensionless) (Bohm, 1989, 1992; Mitchell, 1996); the terminal velocity is then derived from $R e$, which is determined in terms of $X$. The detailed description of generating $X$ and the empirical relationship of $R e-$ $X$ is given in Mitchell (1996) and Mitchell and Heymsfield (2005). Since $X$ is a function of the ice particle mass $(m)$ and the cross-sectional area $(A)$, both of which are parameterized as a power-law function of the maximum dimension 
Table 3. List of empirical and theoretical snow-particle terminal velocity $\left(\mathrm{cm} \mathrm{s}^{-1}\right)$ formulas.

\begin{tabular}{|c|c|c|}
\hline Source & Formula & Particle shape \\
\hline Langleben (1954) & $V_{D}=207 D_{\mathrm{p}}^{0.31}$ & plane dendrite \\
\hline Jiusto and Bosworth (1971) & $V_{D}=104.9 D_{\mathrm{m}}^{0.206}$ & plane dendrite \\
\hline Locatelli and Hobbs (1974) & $V_{D}=64.8 D_{\mathrm{m}}^{0.257}$ & plane dendrite \\
\hline Molthan et al. (2010) & $V_{D}=110.1 D_{\mathrm{m}}^{0.145}$ & plane dendrite \\
\hline Jiusto and Bosworth (1971) & $V_{D}=153 D_{\mathrm{m}}^{0.206}$ & column \\
\hline Matson and Huggins (1980) & $V_{D}=1145 D_{\mathrm{p}}^{0.5}$ & graupel \\
\hline Mitchell (1996) & $\begin{array}{l}V_{D}=\frac{\operatorname{Re} \mu_{\mathrm{a}}}{D_{\mathrm{m}} \rho_{\mathrm{a}}} \\
\operatorname{Re}=\left\{\begin{array}{l}0.04394 X^{0.970}, 0.01<X \leq 10.0 \\
0.06049 X^{0.831}, 10.0<X \leq 585 \\
0.2072 X^{0.638}, 585<X \leq 1.56 \times 10^{5} \\
1.0865 X^{0.499}, 1.56 \times 10^{5}<X \leq 10^{8}\end{array}\right.\end{array}$ & any shape \\
\hline Mitchell and Heymsfield (2005) & $\begin{array}{l}V_{D}=a_{v} D_{\mathrm{m}}^{b_{v}}, R e=a_{1} X^{b 1}, m=\alpha D_{\mathrm{m}}^{\beta}, A=\gamma D_{\mathrm{m}}^{\sigma} \\
a_{v}=a_{1}\left(\frac{\mu_{\mathrm{a}}}{\rho_{\mathrm{a}}}\right)^{\left(1-2 b_{1}\right)}\left(\frac{2 \alpha g}{\rho \alpha \gamma}\right)^{b 1}, b_{v}=b_{1}(\beta-\sigma+2)-1\end{array}$ & any shape \\
\hline
\end{tabular}

of the ice particle $\left(D_{\mathrm{m}}\right)$, the selection of different power-law functions for $m$ and $A$ may lead to large differences in the $X$ value, and thus to large errors in $V_{D}$ (Mitchell, 1996). The advantage of the theoretically based parameterizations, however, is that they can be applied to any particle shape (Table 3).

\subsection{Snow-particle cross-sectional area $A$}

Knowledge of the cross-sectional area of a snow particle is essential for accurate calculation of $\Lambda_{\text {snow }}$ and for the estimation of snow-particle terminal velocity. Snow particles can have dozens of irregular shapes, and it is not realistic to represent the $A$ of all particle shapes accurately using one single theoretical formula. A common approach associating $A$ of a snow particle and its mass $(m)$ is through the definition of a parameter: the particle's maximum dimension, $D_{\mathrm{m}}$. Both $m$ and $A$ are parameterized as power-law functions of $D_{\mathrm{m}}$ : $m=\alpha D_{\mathrm{m}}^{\beta}$ and $A=\gamma D_{\mathrm{m}}^{\sigma}$, where $\alpha, \beta, \gamma$, and $\sigma$ are empirical constants developed from measurements of natural snow particles (e.g. Locatelli and Hobbs, 1974; Mitchell et al., 1990; Mitchell and Arnott, 1994; Mitchell, 1996; Pruppacher and Klett, 1997; Woods et al., 2008). The detailed empirical expressions and related parameters for various snow types were reviewed by Mitchell (1996).

In the present study, four habit types of snow crystals spherical snow crystal, dendrite snow plate, columnar snow crystal, and graupel particle - were chosen for analysis and discussion (Table 4). These are the four habits of snow crystals that occur most frequently as revealed by ground observations (Hobbs et al., 1972); they are believed to be the main habits of snow crystals based on the classification of habit composition as determined from the airborne $2 \mathrm{D}-\mathrm{C}$ probe imagery and ground-based stereomicroscope observations (Woods et al., 2008). As well, current cloud-scale CTMs and numerical weather prediction models only explicitly distinguish and predict a few types of snow crystals, including dendrite snowflake, columnar snow crystal, and graupel (hail) (e.g. Field and Heymsfield, 2003; Thompson et al., 2008; Morrison et al., 2009).

Note that the particle size $D_{\mathrm{m}}$ used in the diameter-based mass and area power-law formulas shown in Table 4 is the maximum dimension for a frozen particle. These relationships can also be represented in terms of $D_{\mathrm{p}}$, the equivalent drop diameter of a snow particle when it melts. The melted mass of a snow particle can be expressed in terms of the diameter of its equivalent water drop as

$m=\rho_{\text {water }} \frac{\pi}{6} D_{\mathrm{p}}^{3}$,

where $\rho_{\text {water }}$ is the water density. The cross-sectional area of a falling snow particle can then be written as

$A=\gamma\left(\frac{\rho_{\text {water } \pi D_{\mathrm{p}}^{3}}}{6 \alpha}\right)^{\frac{\sigma}{\beta}}$ 
Table 4. Snow-particle shapes considered in this study and their mass and cross-sectional area formulas. $D_{\mathrm{m}}$ is the snow crystal maximum diameter $(\mathrm{cm})$.

\begin{tabular}{lll}
\hline $\begin{array}{l}\text { Snow-particle } \\
\text { shape }\end{array}$ & $\begin{array}{l}\text { Mass } \\
m=\alpha D_{\mathrm{m}}{ }^{\beta}[\mathrm{g}]\end{array}$ & $\begin{array}{l}\text { Cross-sectional area } \\
A=\gamma D_{\mathrm{m}}{ }^{\sigma}\left[\mathrm{cm}^{2}\right]\end{array}$ \\
\hline Spheres & $m=0.0524 D_{\mathrm{m}}^{3.00, \mathrm{a}}$ & $A=0.7854 D_{\mathrm{m}}^{2.00, \mathrm{a}}$ \\
Dendrites & $m=0.0022 D_{\mathrm{m}}^{2.19, \mathrm{~b}}$ & $A=0.2285 D_{\mathrm{m}}^{1.88, \mathrm{c}}$ \\
Columns & $m=0.0450 D_{\mathrm{m}}^{3.00, \mathrm{~b}}$ & $A=0.0512 D_{\mathrm{m}}^{1.41, \mathrm{~d}}$ \\
Graupel & $m=0.0490 D_{\mathrm{m}}^{2.80, \mathrm{e}}$ & $A=0.5000 D_{\mathrm{m}}^{2.00, \mathrm{e}}$ \\
\hline
\end{tabular}

${ }^{a}$ Obtained from $m=\rho_{\mathrm{S}}(\pi / 6) D_{\mathrm{m}}^{3}$ and $A=(\pi / 4) D_{\mathrm{m}}^{2}$, with $\rho_{\mathrm{S}}=0.1 \mathrm{~g} \mathrm{~cm}^{-3}$.

${ }^{\mathrm{b}}$ From Woods et al. (2008).

c From Mitchell (1996) for "Aggregates of side planes".

d From Mitchell (1996) for "Rimed long columns".

e From Mitchell (1996) for "Lump graupel".

\section{Sensitivity of theoretical size-resolved $\Lambda_{\text {snow }}$ to input-parameter selections}

From Sect. 2 we know that four component parameters determine $\Lambda_{\text {snow }}$ values and that different formulas have been proposed in the literature for these parameters (see Tables 1-4). The sensitivity of $\Lambda_{\text {snow }}$ to the choice of one of these different formulas for each of these component parameters is discussed below. To perform the numerical sensitivity tests presented below, 100 size bins were used to discretize the size distribution of snow particles, and a second set of 100 size bins were used to discretize the size distribution of aerosol particles. The size ranges considered were $10 \mu \mathrm{m}$ to $10 \mathrm{~mm}$ in water-equivalent particle diameter for snow particles and 0.001 to $100 \mu \mathrm{m}$ in particle diameter for aerosol particles. A constant volume ratio between successive size bins was used for both discretizations. The temperature and pressure were assumed to be $-10^{\circ} \mathrm{C}$ and $1013.5 \mathrm{hPa}$, respectively.

\subsection{Sensitivity of $\Lambda_{\text {snow }}$ to $E$}

Figure 1 compares collection efficiencies $E\left(d_{\mathrm{p}}, D_{\mathrm{p}}\right)$ based on the three formulas listed in Table 1 across the aerosolparticle diameter range from 0.001 to $10 \mu \mathrm{m}$ for collection by monodisperse snow particles with four different shapes and three different maximum sizes $D_{\mathrm{m}}$. Each colour in Fig. 1 represents one formula listed in Table 1, and the different symbols on the lines distinguish the four different snow-particle shapes (Table 4). A strong dependence of $E$ on aerosol-particle size is found for all cases. The ultrafine particles $\left(d_{\mathrm{p}}<0.01 \mu \mathrm{m}\right)$ and large particles $\left(d_{\mathrm{p}}>3 \mu \mathrm{m}\right)$ have the largest $E$ values while particles with $d_{\mathrm{p}}$ around $0.1 \mu \mathrm{m}$ have the smallest $E$ values. This variation is certainly caused by the size-dependence of the collection mechanisms, namely Brownian diffusion, interception, and inertial impaction, considered in the formulas in Table 1 . The contribution of Brownian diffusion to $E$ dominates for the ultrafine particles but decreases rapidly as particle size in- creases; the contribution of inertial impaction becomes significant when the diameter of an aerosol particle is larger than a few microns; and the contribution of the interception mechanism increases with increasing particle size and appears to be important for particles in the diameter range from $1.0 \mu \mathrm{m}$ to a few microns. The combined contributions of the three mechanisms lead to low $E$ values for particles in the size range $0.01 \mu \mathrm{m}<d_{\mathrm{p}}<1.0 \mu \mathrm{m}$. Note that other potential collection mechanisms such as diffusiophoresis, thermophoresis, and electric charges are not included in these formulas. For rain scavenging of atmospheric aerosols, these several mechanisms are less important than the three major mechanisms discussed above and are only significant for particles in the size range of 0.01-1.0 $\mu \mathrm{m}$ (Tinsley et al., 2000; Wang et al., 2010; Santachiara et al., 2012). This is also expected to be the case for snow scavenging of aerosols.

It is evident from Fig. 1 that the $E\left(d_{\mathrm{p}}\right)$ profiles for fixed $D_{\mathrm{m}}$ from the Murakami et al. (1985) and Dick (1990) formulas are not very sensitive to the snow-particle shapes. The four $E\left(d_{\mathrm{p}}\right)$ profiles for four snow-particle shapes based on the same formula are similar. For example, all have a minimum $E$ value at the same particle diameter. $E\left(d_{\mathrm{p}}\right)$ values for these two formulas also differ only by a factor of 2 to 3 between different snow-particle shapes across the entire aerosol-particle size range. Note that all of the formulas in Table 1 depend on snow-particle terminal velocity $V_{D}$ either directly or through the Reynolds and Stokes numbers. In the sensitivity tests presented in Fig. $1, V_{D}$ values were calculated for all snow-particle habits based on the theoretical formula developed by Mitchell and Heymsfield (2005) (see Table 3; the details of the $V_{D}$ calculation will be discussed later in Sect. 3.3). Since different snow-particle shapes have different $A$ and $m$ values (Table 4), this leads to different Reynolds number $R e$ and different best or Davies number values, and thus to different $V_{D}$ values, which caused the small differences in $E\left(d_{\mathrm{p}}\right)$. In contrast, the $E\left(d_{\mathrm{p}}\right)$ profiles for fixed $D_{\mathrm{m}}$ from the Slinn (1984) formula showed a different pattern. The $E\left(d_{\mathrm{p}}\right)$ profiles for the dendrite and column snow-particle shapes are basically the same, and the $E\left(d_{\mathrm{p}}\right)$ profiles for the sphere and graupel particle shapes are also similar. However, the $E\left(d_{\mathrm{p}}\right)$ profiles between these two groups differ significantly, especially for the aerosol-particle sizes where the minimum $E$ value occurs. This is due to values specified for two of the parameters used in Slinn's formula (see Table 1); $\lambda$ and $\alpha$ were given as $10.0 \mu \mathrm{m}$ and 1.0 , respectively, for dendrite and column shapes but $100.0 \mu \mathrm{m}$ and $2 / 3$, respectively, for sphere and graupel shapes.

Differences in $E$ between the Murakami et al. (1985) and Dick (1990) formulas are significant for all aerosol-particle sizes and for all snow-particle sizes and shapes considered here. The largest differences occur for particle diameters around $0.1 \mu \mathrm{m}$, for which the difference can be larger than one order of magnitude. $E$ decreases significantly with increasing collector (i.e. snow particle) size in these two formulas. The difference in $E$ between these two formulas also 
(a)

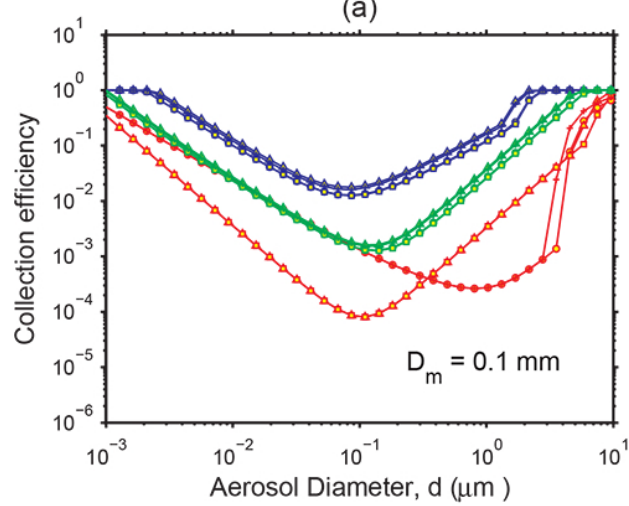

(c)

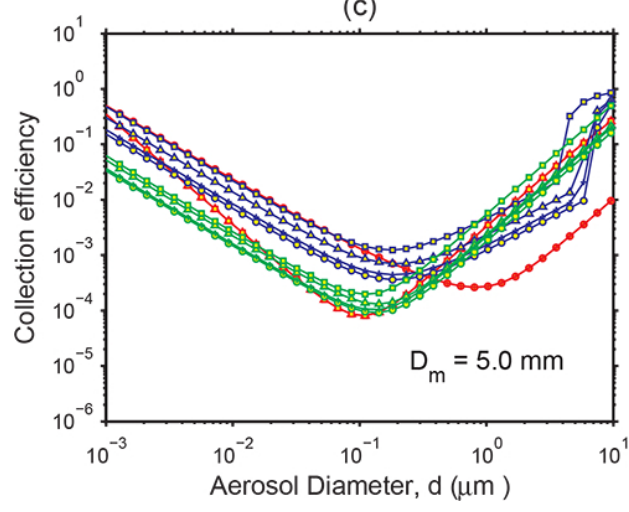

(b)

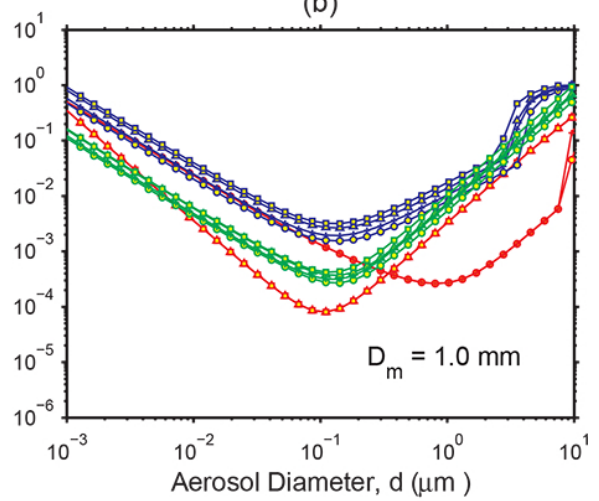

- - Slinn (1984)-- Spheres

$\triangle \_$Slinn (1984)-- Dendrites

$\longrightarrow$ - Slinn (1984)-- Columns

___ Slinn (1984)-- Graupel

- - - Murakami et al.(1985)--Spheres

$\triangle \triangle$ Murakami et al.(1985)--Dendrites

$\longrightarrow$ - Murakami et al.(1985)--Columns

___ Murakami et al.(1985)--Graupel

- - Dick (1990)--Spheres

$\triangle \triangle$ Dick (1990)--Dendrites

$\longrightarrow$ - Dick (1990)--Columns

__ Dick (1990)--Graupel

Fig. 1. Size-resolved snow collection efficiency profiles $E\left(d_{\mathrm{p}}, D_{\mathrm{p}}\right)$ calculated using the three formulas listed in Table 1 (three different colours) for aerosol particles from 0.001 to $10 \mu \mathrm{m}$ in diameter collected by monodisperse snow particles of three different (frozen) sizes: (a) 0.1 ; (b) 1.0 ; and (c) $5.0 \mathrm{~mm}$. Four different snow-particle shapes are considered for each snow-particle size (different symbols in each colour group). Note in (a), (b) and (c) the overlap of red triangle and red square and partial overlap of red circle and red cross; and in (a) the overlap of blue triangle and blue cross and the overlap of blue circle and blue square.

decreases with increasing collector size. The dependence of $E$ on collector size is because larger collectors have larger $V_{D}$ values, and thus larger $R e$ values, which results in smaller $E$ values (see formulas in Table 1). Comparing $E$ values for the Slinn (1984) formula with those from the Murakami et al. (1985) and Dick (1990) formulas, the differences are even larger, especially for smaller collectors (e.g. Fig. 1a). Differences up to nearly three orders of magnitude can be seen for aerosol-particle sizes from 0.1 to $2 \mu \mathrm{m}$. It should be pointed out that the $E$ values for the Slinn (1984) formula do not change much with collector size because $\lambda$ and $\alpha$ values are fixed for all collector sizes, a different behaviour from the other two formulas discussed above.

The sensitivity of $\Lambda_{\text {snow }}$, calculated using Eq. 2, to the choice of the three different formulas for $E$ (Table 1) is illustrated in Fig. 2 for two snowfall intensities (as liquid water equivalent): $0.1 \mathrm{~mm} \mathrm{~h}^{-1}$ (solid line) and $10 \mathrm{~mm} \mathrm{~h}^{-1}$ (symbol line). The snow-particle terminal velocity used for Fig. 2 was that of Mitchell and Heymsfield (2005) (see Table 3), and the snow-particle size spectrum followed Sekhon and Srivastava (1970) (see Table 2). Figure 2 indicates that the differences in $\Lambda_{\text {snow }}$ due to the different $E\left(d_{\mathrm{p}}, D_{\mathrm{p}}\right)$ formulas vary with aerosol-particle size, snow-particle shape, and snowfall intensity. For the largest aerosol particles (i.e. $d_{\mathrm{p}}>10.0 \mu \mathrm{m}$ ), the differences in $\Lambda_{\text {snow }}$ are small (e.g. a factor of 2 ) for both snowfall intensities and all snow-particle shapes due to the very similar $E$ values in this aerosol-particle size range (close to unity; not shown in Fig. 1). For aerosol particles smaller than $10 \mu \mathrm{m}$, a difference of one order of magnitude or larger is seen under all snowfall intensity and snow-particle shape conditions. It can also be seen that the differences in $\Lambda_{\text {snow }}$ are smaller for aerosol particles smaller than $0.01 \mu \mathrm{m}$ than for particles between 0.01 and $10.0 \mu \mathrm{m}$, consistent with the differences in $E$ profiles shown in Fig. 1.

The differences in $E\left(d_{\mathrm{p}}, D_{\mathrm{p}}\right)$ values between the different $E\left(d_{\mathrm{p}}, D_{\mathrm{p}}\right)$ formulas are larger for smaller collectors (i.e. snow particles) than for larger collectors (Fig. 1). For any snow-particle size distribution, lower snow intensities would have more small collectors than stronger snow intensities (see discussion in the next section). Thus, the differences in $\Lambda_{\text {snow }}$ that arise from using different formulas for $E\left(d_{\mathrm{p}}, D_{\mathrm{p}}\right)$ are larger for lower snow intensities (compare the ranges of the solid lines and dashed lines in Fig. 2). 
(a)

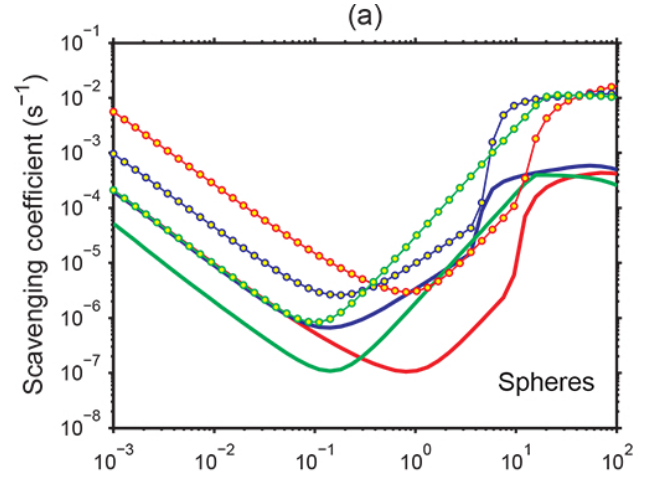

(c)

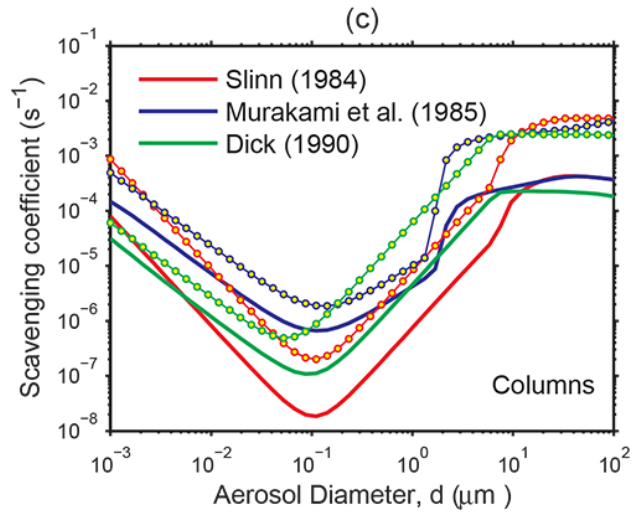

(b)

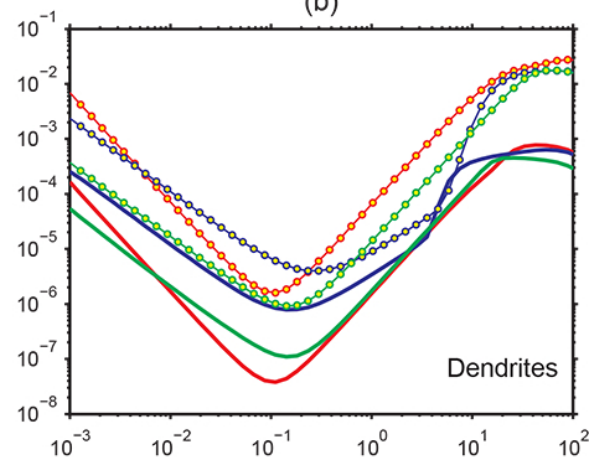

(d)

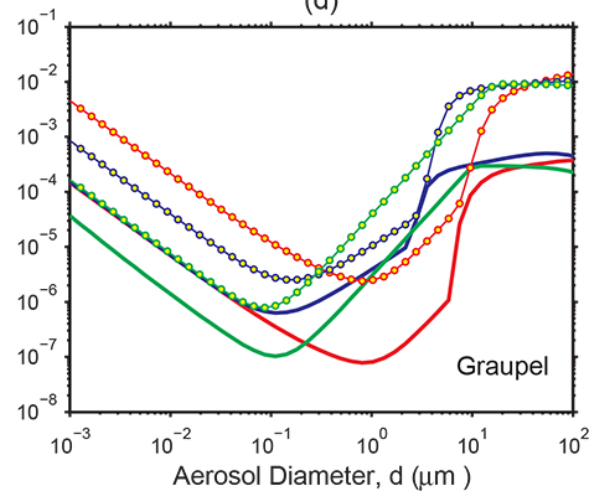

Fig. 2. Size-resolved snow scavenging coefficient profiles $\Lambda_{\text {snow }}$ determined for three different $E\left(d_{\mathrm{p}}, D_{\mathrm{p}}\right)$ formulas (three different colours) under snowfall intensities of 0.1 (solid line) and $10.0 \mathrm{~mm} \mathrm{~h}^{-1}$ (symbol line) for four snow-particle shapes: (a) spheres; (b) dendrites; (c) columns; and (d) graupel.

Figure 2 also suggests that $\Lambda_{\text {snow }}$ values derived from the Murakami et al. (1985) and Dick (1990) formulas agree well (e.g. within a factor of 2) for aerosol particles larger than $1.0 \mu \mathrm{m}$ and differ by a factor of 3 to 4 for aerosol particles smaller than $0.1 \mu \mathrm{m}$ for all snow shapes and snowfall intensities. In contrast, $\Lambda_{\text {snow }}$ values from the Slinn (1984) formula show a large deviation from those of the other two formulas, in particular for the aerosol-particle size range of $0.1 \mu \mathrm{m}<d_{\mathrm{p}}<10.0 \mu \mathrm{m}$, except for the case for dendrites and a light snowfall intensity. Again, this can be explained by the $E$ patterns shown in Fig. 1. These results suggest that the formulation used to describe the collection efficiency is a very important source of uncertainty in estimating $\Lambda_{\text {snow }}$.

\subsection{Sensitivity of $\Lambda_{\text {snow }}$ to $N\left(D_{p}\right)$}

Snow-particle size distributions $\left(N\left(D_{\mathrm{p}}\right)\right)$ generated from the four widely used exponential formulas listed in Table 2 are shown in Fig. 3 for two snowfall intensities (as liquid water equivalent): 0.1 and $1.0 \mathrm{~mm} \mathrm{~h}^{-1}$. The Gunn-Marshall (GM) and the Sekhon-Srivastava $(\mathrm{SS}) N\left(D_{\mathrm{p}}\right)$ profiles are quite close due to their similar values for the intercept parameter $N_{0 \mathrm{e}}$ and slope parameters $\beta_{\mathrm{e}}$ (see Table 2). The MarshallPalmer (MP) distribution differs significantly from those of
GM and SS, and the Scott (SC) distribution is even more different. All four exponential distributions yield large numbers of small snow particles $\left(D_{\mathrm{p}}<0.1 \mathrm{~mm}\right)$. This is due to the limitation in the definition of the exponential formula, which generally predicts maximum number concentration for particle sizes approaching zero (see Eq. 3).

The percentages of snow-particle number concentrations in different size ranges are shown in Table 5 for three of the four snow-particle size distributions and four snowfall intensities. Note that $N_{0 \mathrm{e}}$ is fixed for the MP and SC distributions but decreases with increasing snowfall intensity for the SS distribution (see Table 2). Thus, the total snow-particle number concentrations from the MP and SC distributions increase, and those from the SS decrease with increasing snowfall intensity (Table 5). The total number concentrations from different size distributions can differ from less than one order of magnitude to more than two orders of magnitude, depending on snowfall intensity. For all of the size distributions, however, the percentages of the smallest snow particles $(<0.1 \mathrm{~mm})$ decrease, and those of the largest snow particles $(>1 \mathrm{~mm})$ increase with increasing snowfall intensity. This can also be seen from Fig. 3, in which all of the snowparticle size distribution profiles shift to larger snow-particle sizes with increasing snowfall intensity. 
Table 5. Total snow-particle number concentration $\left(N_{\text {total }}, \mathrm{m}^{-3}\right)$ for three of the number size distributions listed in Table 2 for four different snowfall intensities (as liquid water equivalent). MP denotes the Marshall and Palmer (1948) distribution, SC the Scott (1982) distribution, and SS the Sekhon and Srivastava (1970) distribution. $f_{1}, f_{2}$, and $f_{3}$ are the percentages of the snow particles with equivalent melted diameter smaller than $0.1 \mathrm{~mm}$, between 0.1 and $1.0 \mathrm{~mm}$, and larger than $1 \mathrm{~mm}$, respectively.

\begin{tabular}{|c|c|c|c|c|c|c|c|c|c|c|c|c|}
\hline \multirow[t]{2}{*}{$R\left(\mathrm{~mm} \mathrm{~h}^{-1}\right)$} & \multicolumn{4}{|c|}{ MP } & \multicolumn{4}{|c|}{$\mathrm{SC}$} & \multicolumn{4}{|c|}{ SS } \\
\hline & $\begin{array}{l}N_{\text {total }} \\
\left(\mathrm{m}^{-3}\right)\end{array}$ & $\begin{array}{c}f_{1} \\
(\%)\end{array}$ & $\begin{array}{c}f_{2} \\
(\%)\end{array}$ & $\begin{array}{c}f_{3} \\
(\%)\end{array}$ & $\begin{array}{l}N_{\text {total }} \\
\left(\mathrm{m}^{-3}\right)\end{array}$ & $\begin{array}{c}f_{1} \\
(\%)\end{array}$ & $\begin{array}{c}f_{2} \\
(\%)\end{array}$ & $\begin{array}{c}f_{3} \\
(\%)\end{array}$ & $\begin{array}{l}N_{\text {total }} \\
\left(\mathrm{m}^{-3}\right)\end{array}$ & $\begin{array}{r}f_{1} \\
(\%)\end{array}$ & $\begin{array}{c}f_{2} \\
(\%)\end{array}$ & $\begin{array}{r}f_{3} \\
(\%)\end{array}$ \\
\hline 0.1 & 1126.5 & 46.4 & 53.4 & 0.2 & 8381.3 & 37.0 & 63.0 & 0.0 & 3164.7 & 45.4 & 54.3 & 0.2 \\
\hline 1.0 & 1872.5 & 31.9 & 66.1 & 2.0 & 17238.9 & 20.2 & 79.7 & 0.1 & 1066.1 & 19.3 & 69.5 & 11.2 \\
\hline 5.0 & 2655.4 & 24.0 & 69.9 & 6.1 & 28474.7 & 12.8 & 85.4 & 1.8 & 490.1 & 9.9 & 55.5 & 34.6 \\
\hline 10.0 & 3083.2 & 21.1 & 70.0 & 8.9 & 35332.7 & 10.5 & 85.6 & 3.9 & 349.9 & 7.3 & 46.7 & 46.0 \\
\hline
\end{tabular}

(a)

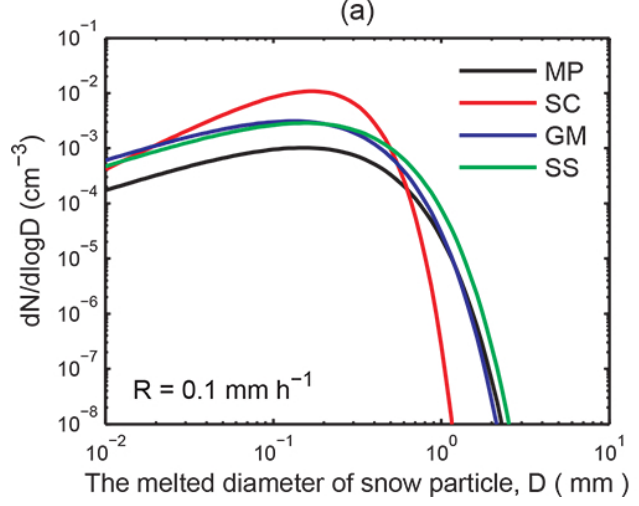

(b)

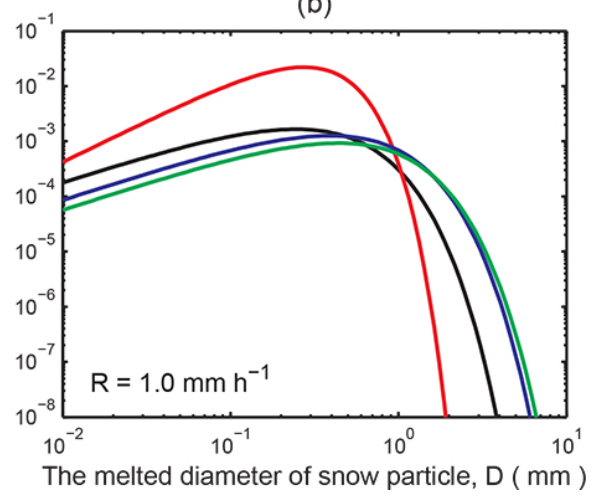

Fig. 3. Snow-particle number size distributions under snowfall intensities (as liquid water equivalent) of (a) $0.1 \mathrm{~mm} \mathrm{~h}^{-1}$ and (b) $1.0 \mathrm{~mm} \mathrm{~h}^{-1}$ for four different formulas: MP - Marshall and Palmer (1948); SC - Scott (1982); GM - Gunn and Marshall (1958); and SS - Sekhon and Srivastava (1970).

Figure 4 shows the sensitivity of $\Lambda_{\text {snow }}$ to the four different snow-particle number size distributions $N\left(D_{\mathrm{p}}\right)$ considered in Fig. 3 for four snow-particle shapes and two snowfall intensities (as liquid water equivalent): $0.1 \mathrm{~mm} \mathrm{~h}^{-1}$ and $10 \mathrm{~mm} \mathrm{~h}^{-1}$. $V_{D}$ and $E\left(d_{\mathrm{p}}, D_{\mathrm{p}}\right)$ were assumed to follow the theoretical formulas of Mitchell and Heymsfield (2005) and Murakami et al. (1985), respectively. Note that the magnitudes of the uncertainties in $\Lambda_{\text {snow }}$ caused by $N\left(D_{\mathrm{p}}\right)$ are similar if other formulas are used for $V_{D}$ and $E\left(d_{\mathrm{p}}, D_{\mathrm{p}}\right)$ (see Sect. 4.1), but the Mitchell and Heymsfield (2005) formula was used here because it is applicable to all snow-particle shapes. Differences in $\Lambda_{\text {snow }}$ values derived from these different $N\left(D_{\mathrm{p}}\right)$ formulas are up to one order of magnitude for all aerosolparticle sizes for a light snowfall intensity $\left(0.1 \mathrm{~mm} \mathrm{~h}^{-1}\right)$. The differences in $\Lambda_{\text {snow }}$ also increase with increasing snowfall intensity and can be larger than one order of magnitude for a very strong snowfall intensity (e.g. $10 \mathrm{~mm} \mathrm{~h}^{-1}$ ). However, it should be pointed out that the increase in the uncertainties of $\Lambda_{\text {snow }}$ with increasing snow intensity is not a linear relationship because different $N\left(D_{\mathrm{p}}\right)$ formulas respond differently to increasing snow intensity. This relationship was confirmed by a full set of sensitivity tests covering a large range of snow intensities (results not presented here). The dependence of
$\Lambda_{\text {snow }}$ on snowfall intensity is also greater for some $N\left(D_{\mathrm{p}}\right)$ formulas than others. Based on the $\Lambda_{\text {snow }}$ profiles shown in Fig. 4, we can conclude that in general different assumptions for $N\left(D_{\mathrm{p}}\right)$ contribute an uncertainty to the $\Lambda_{\text {snow }}$ profile of about one order of magnitude for all aerosol-particle sizes under all snow-particle shape and snowfall intensity conditions.

\subsection{Sensitivity of $\Lambda_{\text {snow }}$ to $V_{D}$ and $A$}

Figure 5a shows the terminal velocities $V_{D}$ of snow particles with four different shapes calculated from empirical and theoretical formulas selected from Table 3. Each colour represents one particle shape, and each line represents one formula. Note that the theoretical formula of Mitchell and Heymsfield (2005) was considered to apply to any kind of snow-particle shape. Results from the theoretical formula of Mitchell (1996) are not shown in the figure because the calculated values are quite close to those from Mitchell and Heymsfield (2005). For snow particles larger than $0.2 \mathrm{~mm}$, $V_{D}$ values for the same particle shape but based on different formulas are generally within a factor of 5 ; however, the differences can be larger than a factor of 10 if considering both 
(a)

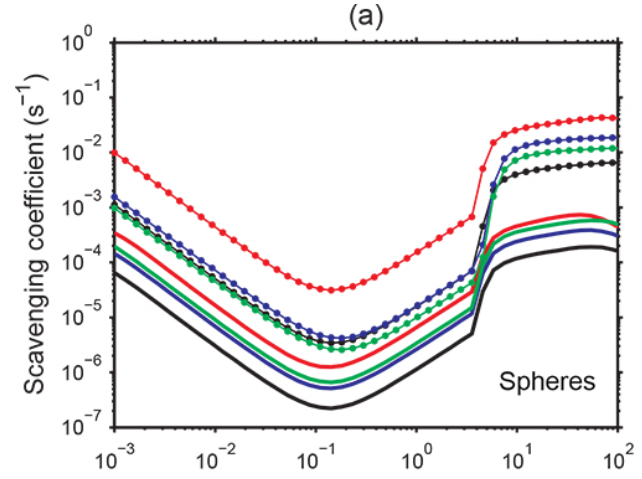

(c)

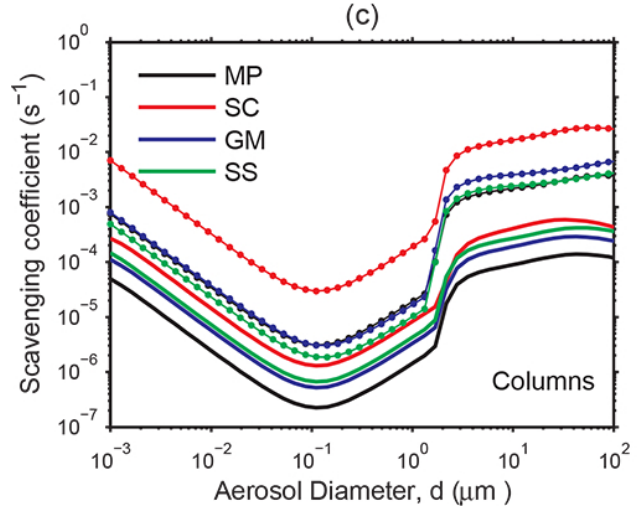

(b)

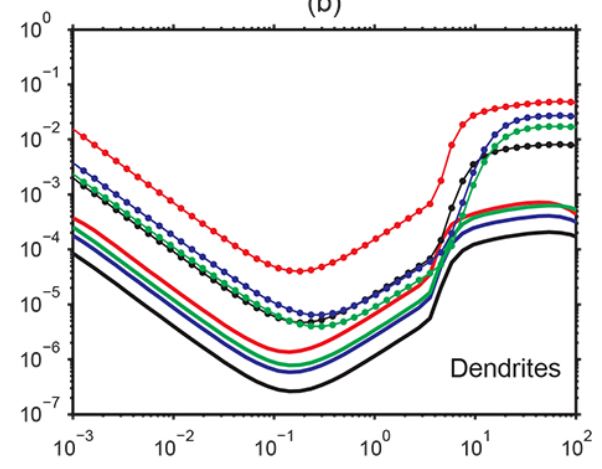

(d)

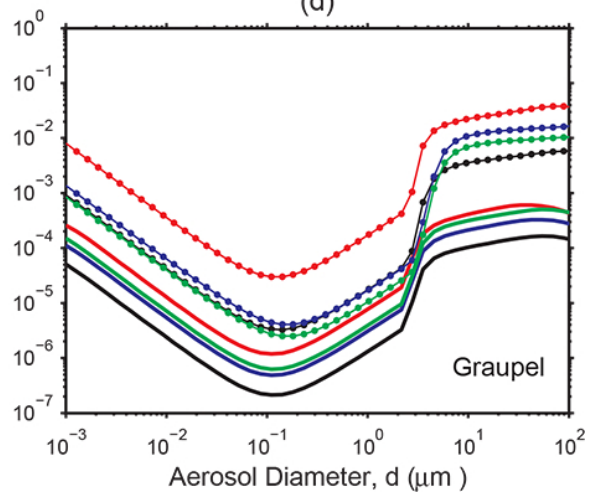

Fig. 4. Size-resolved snow scavenging coefficient profiles obtained using the four different snow-particle number size distributions shown in Fig. 3 for snowfall intensities (as liquid water equivalent) of 0.1 (solid line) and $10 \mathrm{~mm} \mathrm{~h}^{-1}$ (symbol line) for four different snow-particle shapes.

different particle shapes and different formulas. For snow particles smaller than $0.2 \mathrm{~mm}$, the differences in $V_{D}$ can be up to two orders of magnitude and generally increase rapidly with decreasing snow-particle size. As well, $V_{D}$ values from all of the empirical formulas are larger than those from the theoretical formula of Mitchell and Heymsfield (2005) for all particle shapes. The best agreement between the empirical and theoretical formulas is for the dendrite shape and snow particles larger than $0.2 \mathrm{~mm}$.

Figure $5 \mathrm{~b}$ shows the cross-sectional area $A$ of a snow particle versus its maximum dimension for four different snowparticle shapes based on the power-law formulas listed in Table 4 . The differences in $A$ between different snow-particle shapes increases from a factor of 3 to a factor of more than 10 as snow-particle size increases from 0.1 to $10 \mathrm{~mm}$.

The results of sensitivity tests conducted to investigate the influence of $V_{D}$ and $A$ on $\Lambda_{\text {snow }}$ for four different snowparticle shapes and three different snowfall intensities $(0.1$, 1.0 and $10 \mathrm{~mm} \mathrm{~h}^{-1}$ as liquid water equivalent) are shown in Fig. 6. $\Lambda_{\text {snow }}$ profiles were calculated for the nine $V_{D}$ profiles shown in Fig. 5a and the four $A$ profiles shown in Fig. 5b for each snowfall intensity. Note that most $V_{D}$ and all $A$ formulas are empirical, and both quantities are parameterized as simple functions of snow-particle diameter (in water equiva- lent). The physical reason for the differences in $\Lambda_{\text {snow }}$ from using different $V_{D}$ and $A$ formulas is simply that the faster the falling speed or the larger the cross-sectional area of a collector, the faster the collection process will happen. Thus, formulas giving larger $V_{D}$ or $A$ values will result in larger $\Lambda_{\text {snow }}$ values. All of the sensitivity tests shown in this figure used the snow-particle size spectrum formula of Sekhon and Srivastava (1970) (Table 2) and the collection efficiency formula of Murakami et al. (1985) (Table 1). As in Fig. 5a, each colour in Fig. 6 represents one snow-particle shape, and each line represents one $V_{D}$ formula. It is also evident from Fig. 5b that each snow-particle shape only has one formula available for $A$. Thus, the influence of $V_{D}$ on $\Lambda_{\text {snow }}$ can be identified by comparing $\Lambda_{\text {snow }}$ profiles for the same snowparticle shape (i.e. same coloured lines), while the influence of $A$ on $\Lambda_{\text {snow }}$ can be identified by comparing $\Lambda_{\text {snow }}$ profiles based on the same $V_{D}$ formula (e.g. the four solid lines using the formula of Mitchell and Heymsfield, 2005). The overall uncertainty in the $\Lambda_{\text {snow }}$ profile shown in Fig. 6 is thus due to the combination of influences from both $V_{D}$ and $A$.

Figure 6 shows that $\Lambda_{\text {snow }}$ may vary by a factor of 2 to 3 for the same snow-particle shape for all aerosol-particle sizes if different $V_{D}$ formulas are used, and it may also vary by a factor of 2 to 3 for different snow-particle shapes even 
(a)

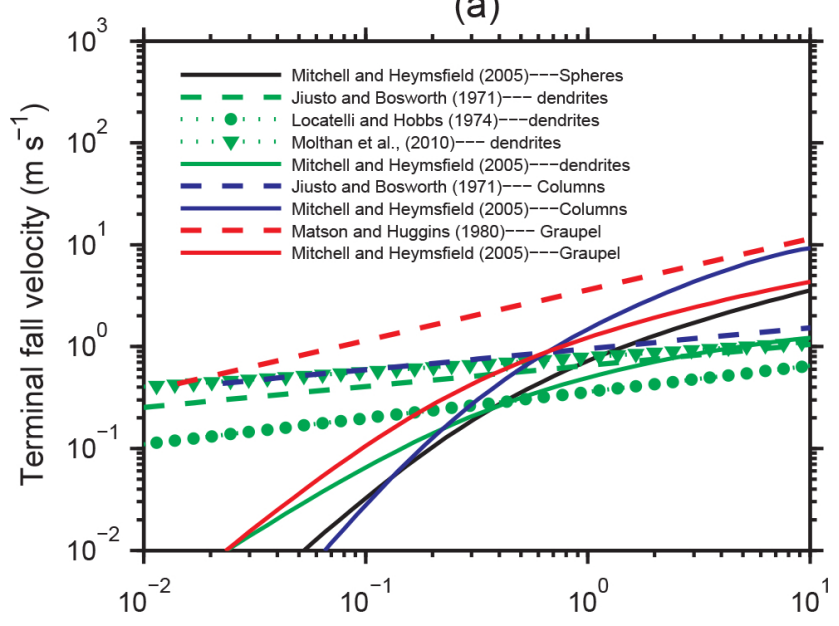

(b)

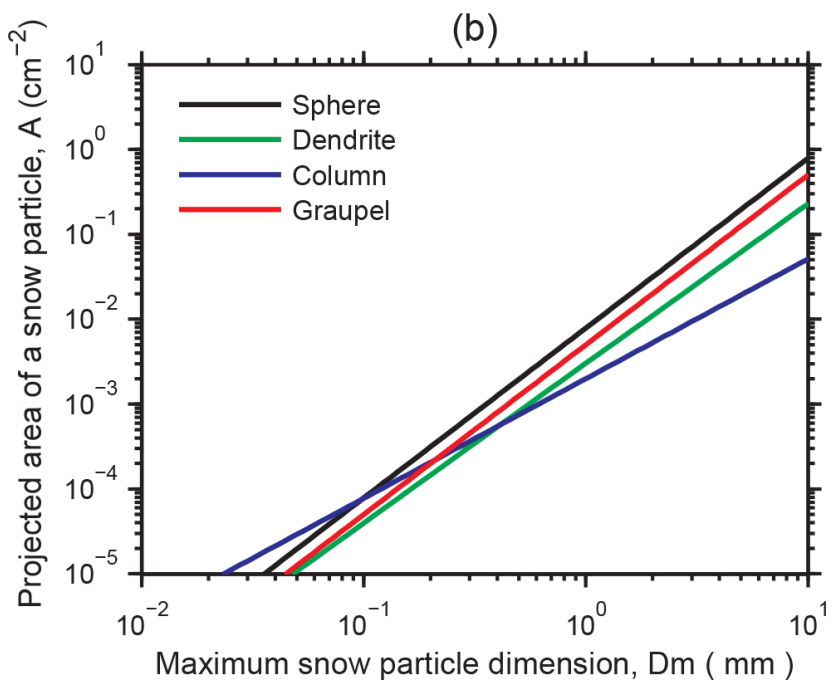

Fig. 5. Snow-particle (a) terminal velocity and (b) cross-sectional area vs. maximum snow-particle dimension derived from different parameterizations (see Tables 3 and 4).

for the same $V_{D}$ formula. The combined uncertainties from both $V_{D}$ and $A$ can thus be as high as a factor of $10 . \Lambda_{\text {snow }}$ values also increase with increasing snowfall intensity, as do the uncertainties in $\Lambda_{\text {snow }}$ values. While the uncertainty in $\Lambda_{\text {snow }}$ caused by uncertainties in either $V_{D}$ or $A$ is smaller than those associated with the representation of $E\left(d_{\mathrm{p}}, D_{\mathrm{p}}\right)$ or $N\left(D_{\mathrm{p}}\right)$, the combined uncertainty due to $V_{D}$ and $A$ can be comparable to the other two factors in some cases (e.g. for large aerosol particles and for strong snowfall intensity; compare Fig. 6c with Fig. 2). It is also worth noting that the uncertainties in $\Lambda$ caused by $V_{D}$ are larger for the snow conditions discussed here than for the rain conditions discussed in Wang et al. (2010), and the largest uncertainties under snow conditions are for large aerosol particles vs. submicron aerosol particles under rain conditions. Thus, significant dif- ferences exist in the uncertainties associated with $\Lambda$ between rain and snow conditions.

\section{Assessment of size-resolved $\Lambda_{\text {snow }}$ parameterizations}

\subsection{Uncertainties in theoretical estimates of size-resolved $\Lambda_{\text {snow }}$ profiles}

As discussed in the previous sections, theoretically based parameterizations of $\Lambda_{\text {snow }}$ require knowledge of $E\left(d_{\mathrm{p}}, D_{\mathrm{p}}\right)$, $N\left(D_{\mathrm{p}}\right), V_{D}$, and $A$. However, due to the natural variability of snow-particle shapes and densities, the limited experimental evidence, and the complexity of microphysical collection processes, there has not been any agreement or consensus in the modelling community as to which formulas should be used for the above-mentioned component parameters in the calculation of $\Lambda_{\text {snow }}$. For example, Feng (2009) proposed a size-resolved model for below-cloud snow scavenging, in which $E\left(d_{\mathrm{p}}, D_{\mathrm{p}}\right)$ was based on a combination of schemes by Martin et al. (1980), Miller and Wang (1989), and Murakami et al. (1985). $N\left(D_{\mathrm{p}}\right)$ followed Sekhon and Srivastava (1970), and $V_{D}$ and $A$ followed Mitchell (1996). Croft et al. (2009) also proposed a size-resolved parameterization for belowcloud snow scavenging, in which $E$ followed Dick (1990) or Slinn (1984), but all snow particles were assumed to be $30 \mu \mathrm{g}$ in mass and $0.5 \mathrm{~mm}$ in radius and to fall at $80 \mathrm{~cm} \mathrm{~s}^{-1}$. Gong et al. (2006) parameterized aerosol scavenging by snow based on the Slinn (1984) formula for $E$ and assuming a stellar shape for snow crystals when $-25^{\circ} \mathrm{C}<T<0^{\circ} \mathrm{C}$ and a graupel shape when $T<-25^{\circ} \mathrm{C}$.

In this section, the uncertainties in existing theoretical size-resolved $\Lambda_{\text {snow }}$ parameterizations were investigated using various combinations of the available formulas for the above-mentioned component parameters. Three semiempirical formulas for $E\left(d_{\mathrm{p}}, D_{\mathrm{p}}\right)$ (Slinn, 1984; Murakami et al., 1985; and Dick, 1990; see Table 1 and Sect. 2.1) and three formulas for $N\left(D_{\mathrm{p}}\right)$ (SS - Sekhon and Srivastava (1970); SC - Scott (1982); and MP - Marshall and Palmer (1948); see Table 2 and Sect. 2.2) were combined together to generate nine sensitivity tests for each of four snow-particle shapes (Fig. 7). The $V_{D}$ formula of Mitchell and Heymsfield (2005) was used in every sensitivity test because this is the only formula applicable to all snow-particle shapes. This formula is a physically based parameterization, and it seems to predict more reasonable $V_{D}$ values for small snow particles (i.e. $D_{\mathrm{m}}<0.5 \mathrm{~mm}$ ) than empirically based formulas (see Sect. 3.3). Besides, the uncertainty in $\Lambda_{\text {snow }}$ values due to the specification of $V_{D}$ is much smaller than those introduced by the specification of $E\left(d_{\mathrm{p}}, D_{\mathrm{p}}\right)$ and $N\left(D_{\mathrm{p}}\right)$ (Sect. 3.3). Note that uncertainties from various $A$ formulas are implicitly included in different snow-particle shapes, as can be seen by comparing the four panels in both Figs. 7 and 8.

Under light snowfall intensities (e.g. $0.1 \mathrm{~mm} \mathrm{~h}^{-1}$ in Fig. 7), the uncertainties in the calculated $\Lambda_{\text {snow }}$ are generally 

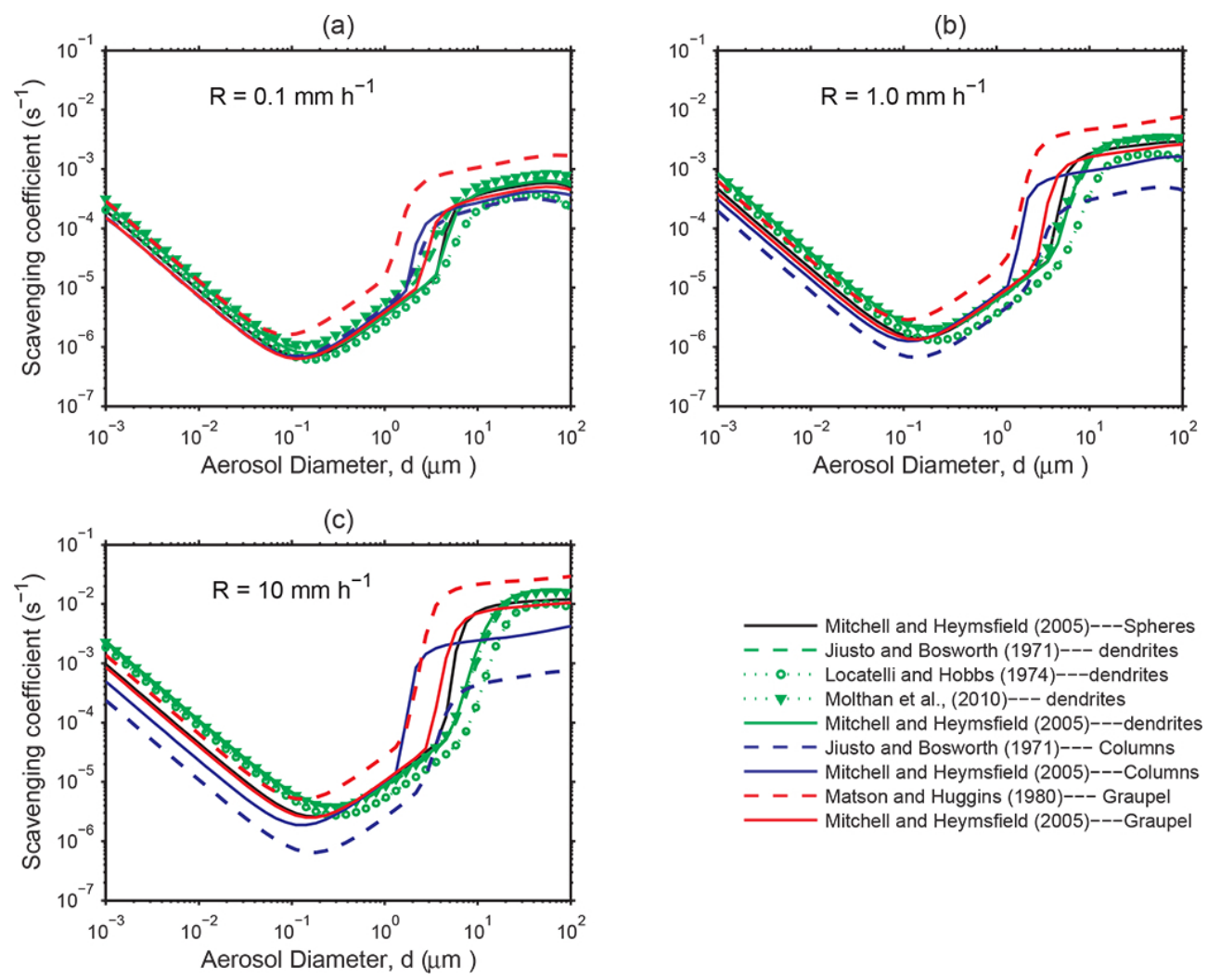

Fig. 6. Size-resolved snow scavenging coefficients $\Lambda_{\text {snow }}$ derived from using different terminal velocity parameterizations for snowfall intensities (as liquid water equivalent) of (a) 0.1 , (b) 1.0 , and (c) $10 \mathrm{~mm} \mathrm{~h}^{-1}$. Note that among the four green lines, the circle one is at the bottom and the other three are close to each other.

in the range of one to two orders of magnitude for very small (i.e. $d_{\mathrm{p}}<0.01 \mu \mathrm{m}$ ) and very large (i.e. $d_{\mathrm{p}}>10 \mu \mathrm{m}$ ) aerosol particles. The uncertainties are much larger for the median size aerosols (i.e. two orders of magnitude or more). The largest uncertainty occurs at an aerosol-particle size of around $0.1 \mu \mathrm{m}$ for dendrite and column habits and at an aerosol-particle size of around $1 \mu \mathrm{m}$ for sphere and graupel habits. This difference is largely associated with snowparticle shape caused by the differences in $E\left(d_{\mathrm{p}}, D_{\mathrm{p}}\right)$ profiles for different snow-particle shapes (as shown in Fig. 2). The ranges of $\Lambda_{\text {snow }}$ values for any aerosol-particle size are also different for different snow-particle shapes as can be seen by comparing the four Fig. 7 panels, which is due in part to the impact of different $A$ formulas on the calculated $\Lambda_{\text {snow }}$ values.

It was shown in Sect. 3 that, for a snowfall intensity (as liquid water equivalent) of $0.1 \mathrm{~mm} \mathrm{~h}^{-1}$, different $E\left(d_{\mathrm{p}}, D_{\mathrm{p}}\right)$ formulas can cause uncertainties in $\Lambda_{\text {snow }}$ of one to two orders of magnitude, and different $N\left(D_{\mathrm{p}}\right)$ formulas can cause uncertainties in $\Lambda_{\text {snow }}$ of one order of magnitude, depending on aerosol-particle size. As shown in Fig. 7, the combined uncertainties from both $E\left(d_{\mathrm{p}}, D_{\mathrm{p}}\right)$ and $N\left(D_{\mathrm{p}}\right)$ are larger than those caused by the individual parameters for all aerosol sizes. Thus, the uncertainties in $\Lambda_{\text {snow }}$ values from each indi- vidual parameter can either cancel each other (i.e. profiles close together) or enhance each other (i.e. profiles further apart).

Figure 8 shows a similar comparison to Fig. 7 but for a snowfall intensity of $1 \mathrm{~mm} \mathrm{~h}^{-1}$. When snowfall intensity increases, $\Lambda_{\text {snow }}$ values also increase for all aerosol-particle sizes (compare Fig. 8 with Fig. 7; note the different scales for the $y$ axes), as do uncertainties in the $\Lambda_{\text {snow }}$ values. The increases in uncertainty are larger for small aerosol particles $(0.001-0.1 \mu \mathrm{m})$ than for large particles. Comparing the ratio of the maximum to the minimum $\Lambda_{\text {snow }}$ for each individual aerosol size using data in Figs. 7 and 8, respectively, it was found that this ratio increased by $30-60 \%$ for all four snowparticle shapes for ultrafine aerosol particles $\left(d_{\mathrm{p}}<0.01 \mu \mathrm{m}\right)$, $10-25 \%$ for particles in the diameter size range from 0.01 to $10 \mu \mathrm{m}$, and $15 \%$ for very large particles $\left(d_{\mathrm{p}}>10 \mu \mathrm{m}\right)$ when the snowfall intensity increased from 0.1 to $1.0 \mathrm{~mm} \mathrm{~h}^{-1}$. Apparently, some formulas are more sensitive to snowfall intensity than others are for smaller aerosol particles. The uncertainties in $\Lambda_{\text {snow }}$ can be as high as two orders of magnitude (e.g. near $d_{\mathrm{p}}=0.1 \mu \mathrm{m}$ for dendrite and column habits and $d_{\mathrm{p}}=1 \mu \mathrm{m}$ for sphere and graupel habits). From Sect. 3.2 it is known that the differences in the total number of snow particles between different $N\left(D_{\mathrm{p}}\right)$ formulas increase with 
(a)

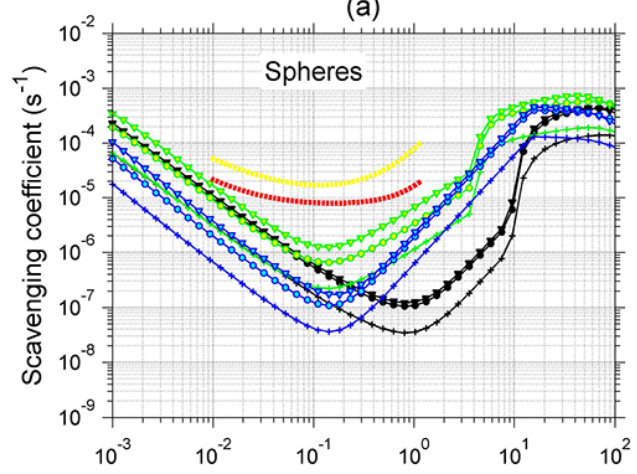

(c)

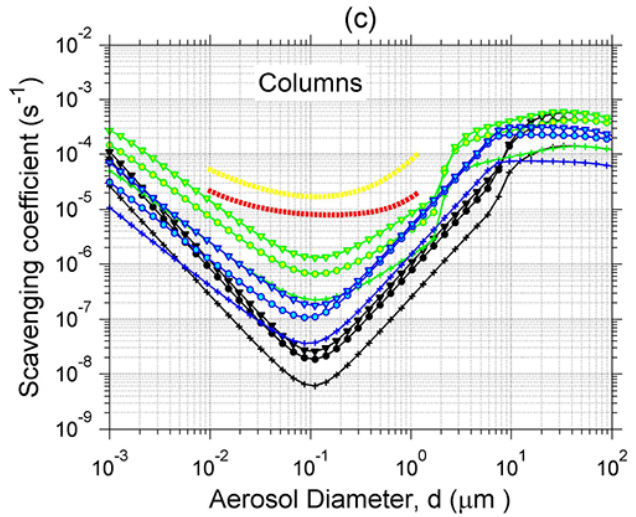

(b)

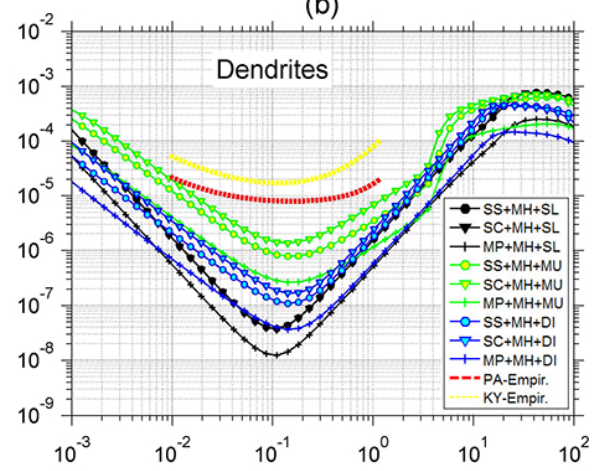

(d)

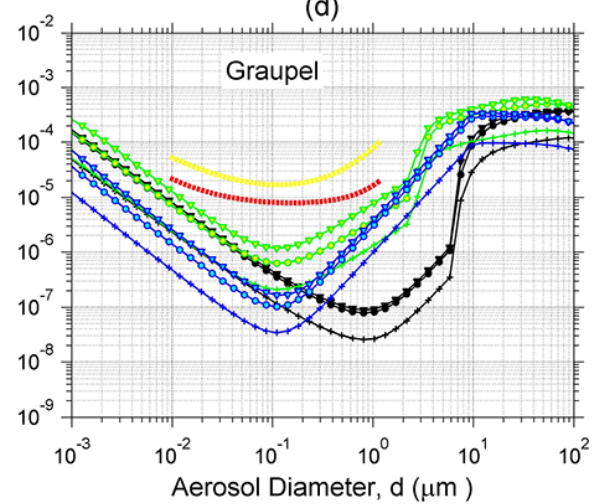

Fig. 7. Size-resolved $\Lambda_{\text {snow }}$ profiles derived from nine theoretical parameterizations generated by a combination of three different $E\left(d_{\mathrm{p}}, D_{\mathrm{p}}\right)$ and three different $N\left(D_{\mathrm{p}}\right)$ formulas for a snowfall intensity (as liquid water equivalent) of $0.1 \mathrm{~mm} \mathrm{~h}^{-1}$ for four different snow-particle shapes: (a) spheres; (b) dendrites; (c) columns; and (d) graupel. The following abbreviations are used: SS - Sekhon and Srivastava (1970); SC Scott (1982); MP - Marshall and Palmer (1948); MH - Mitchell and Heymsfield (2005); SL - Slinn (1984); MU - Murakami et al. (1985); and DI - Dick (1990). Also shown are two empirical results: PA-Empir. $-\Lambda_{\text {snow }}$ calculated from Paramonov et al. (2011) and, KY-Empir. $\Lambda_{\text {snow }}$ calculated from Kyrö et al. (2009), which are only valid for aerosol particles with diameters between 0.01 and $1.0 \mu \mathrm{m}$.

increasing snowfall intensity. This behaviour at least partly explains the increased uncertainties in $\Lambda_{\text {snow }}$ with decreasing aerosol-particle size.

It is worth noting that a full set of sensitivity tests was conducted using all possible combinations of the formulas listed in Tables 1-4 covering a range of precipitation intensities from 0.001 to $10 \mathrm{~mm} \mathrm{~h}^{-1}$ (liquid water equivalent). Based on this complete set of sensitivity tests, it was found that that the uncertainties shown in Figs. 7 and 8 could be further increased by a factor of 2 or so if additional $V_{D}$ formulas were included in the figures, which agrees with the findings shown in Fig. 6. These tests also confirmed that $\Lambda_{\text {snow }}$ magnitudes increase further for all aerosol-particle sizes compared to Figs. 7 and 8 if snowfall intensity increases to $10 \mathrm{~mm} \mathrm{~h}^{-1}$ and the magnitude of the uncertainties in $\Lambda_{\text {snow }}$ increases as well.

\subsection{Comparison between theoretically and empirically estimated $\Lambda_{\text {snow }}$ profiles}

The only way of evaluating the accuracy and applicability of theoretical $\Lambda_{\text {snow }}$ formulas is to compare them with measurements. One practical issue, however, is that the availability of size-resolved $\Lambda_{\text {snow }}$ data from measurements is very limited (Kyrö et al., 2009; Paramonov et al., 2011). A more fundamental issue with comparing measured $\Lambda_{\text {snow }}$ values with theoretical ones is that they are not exactly comparable because of the greater number of physical mechanisms influencing field measurements relative to the mechanisms considered in theoretical $\Lambda_{\text {snow }}$ formulations. This incommensurability has been demonstrated and discussed previously for cases of rain scavenging of atmospheric aerosol particles (Flossman et al., 1991; Andronache et al., 2006; Wang et al., 2011; Quérel et al., 2013). It is thus unrealistic to expect exact agreement between theoretically and empirically derived $\Lambda_{\text {snow }}$ values. Nevertheless, field measurements can serve as constraints (i.e. upper bounds) to the theoretical formulas. 
(a)

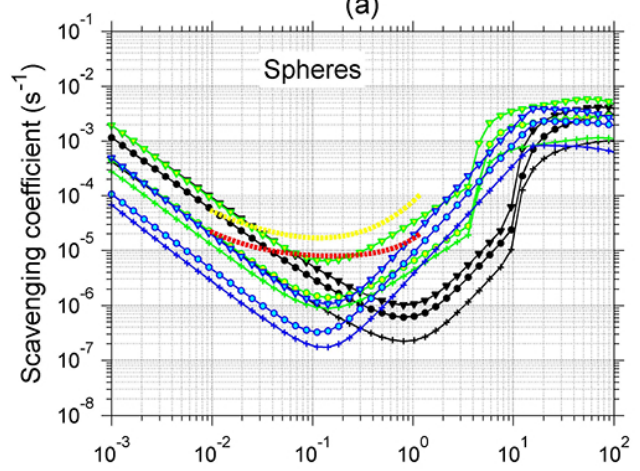

(c)

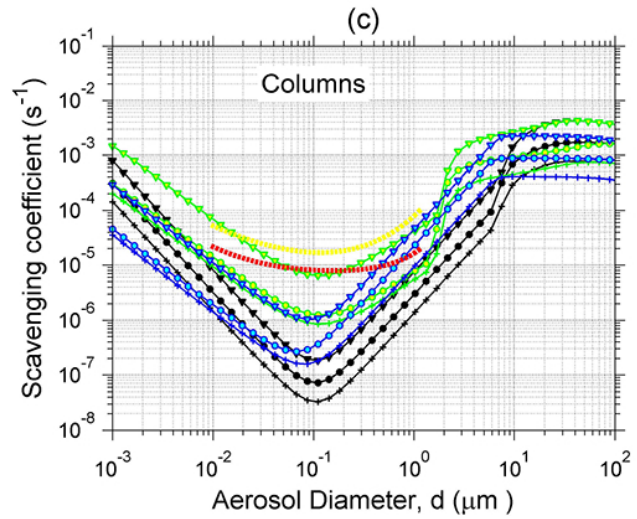

(b)

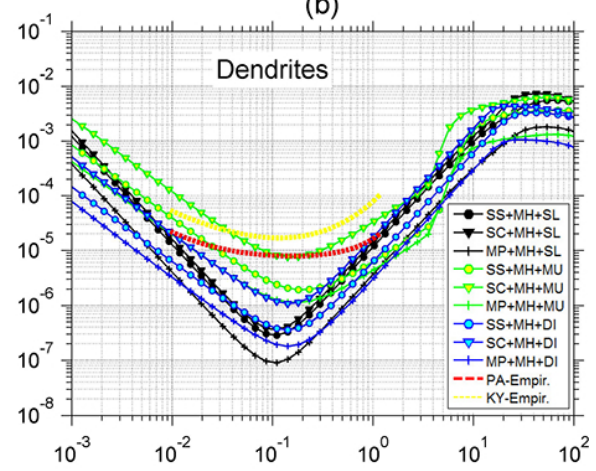

(d)

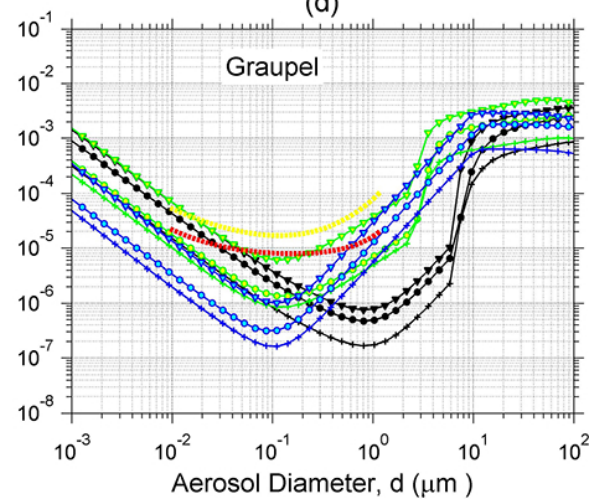

Fig. 8. Same as in Fig. 7 but for a snowfall intensity of $1.0 \mathrm{~mm} \mathrm{~h}^{-1}$ (note change in $y$ axis range with respect to Fig. 7).

$\Lambda_{\text {snow }}$ values calculated using two empirical formulas, one from Kyrö et al. (2009) (Appendix B) and one from Paramonov et al. (2011) (Appendix C), are also shown in Figs. 7 and 8. The empirical formula of Kyrö et al. (2009) was developed based on four years of field data collected in a rural background environment in Finland and only depends on particle size. Snowfall intensities during the measurement period were generally low, with a median value of $0.2 \mathrm{~mm} \mathrm{~h}^{-1}$ (as liquid water equivalent). The formula of Paramonov et al. (2011) was developed based on four winters of field measurements in an urban environment in Finland. In this study, the measurements sampled a variety of different snow-particle shapes and snowfall intensities (as liquid water equivalent) from 0.1 to $1.2 \mathrm{~mm} \mathrm{~h}^{-1}$. However, snowfall intensities were not evenly distributed within this range: nearly $60 \%$ of snow events had intensities of $\leq 0.2 \mathrm{~mm} \mathrm{~h}^{-1}$. The Paramonov et al. (2011) study also found a strong dependence of $\Lambda_{\text {snow }}$ on ambient relative humidity (RH) and a weak dependence on snowfall intensity. Thus, their empirical $\Lambda_{\text {snow }}$ formula is a function of RH but, like the Kyrö et al. (2009) formula, does not depend on snowfall intensity. The dependence of $\Lambda_{\text {snow }}$ on RH might be because the higher the RH, the stickier the snow particles will be, whereas the weak dependence of $\Lambda_{\text {snow }}$ on snowfall intensity might be due to the small number of snowfall intensities sampled during the measurement period. Both empirical formulas are valid only for an aerosol-particle diameter range of 0.01$1.0 \mu \mathrm{m}$. Since neither of the empirical formulas depends on snowfall intensity, the same dashed curves are plotted in each panel of Figs. 7 and 8 for comparison. However, it should be kept in mind that both formulas should be more comparable with Fig. 7 (with a snowfall intensity of $0.1 \mathrm{~mm} \mathrm{~h}^{-1}$ ) than with Fig. 8 (with a snowfall intensity of $1.0 \mathrm{~mm} \mathrm{~h}^{-1}$ ) according to the snowfall intensity distributions in the field measurements. Note that RH was taken to be $90 \%$ in the calculation of $\Lambda_{\text {snow }}$ using the Paramonov et al. (2011) formula.

It can be seen from Fig. 7 that the two empirical formulas reasonably agree with each other, with differences mostly within a factor of 2 to 3 depending on aerosol-particle size. These differences may be attributable to different snow conditions, aerosol size distributions, and data selection criteria (Paramonov et al., 2011). As expected, all of the theoretical $\Lambda_{\text {snow }}$ values are lower than the empirical $\Lambda_{\text {snow }}$ values. Even the upper-range values of the theoretically estimated values are still more than five times lower than the empirical ones for aerosol particles around $0.1 \mu \mathrm{m}$ in diameter, although the differences become much smaller for other aerosol-particle sizes. Looking at Fig. 8, the upper-range values of the theoretically estimated values are similar to the empirical ones for this case in which the snowfall intensity has been increased to $1.0 \mathrm{~mm} \mathrm{~h}^{-1}$. However, this is somewhat expected. As noted above the empirical formulas for $\Lambda_{\text {snow }}$ do not increase with 
increasing snowfall intensity as the theoretical formulas do, and the empirical formulas are based mainly on measurements under conditions with snowfall intensities in the $0.1-$ $0.5 \mathrm{~mm} \mathrm{~h}^{-1}$ range, lower than the snowfall intensity considered in Fig. 8.

Bearing in mind the limited available field data, the comparisons shown in Figs. 7 and 8 suggest that theoretical estimates of $\Lambda_{\text {snow }}$ will be lower than field measurements and that some of the differences may be explained by known factors if the findings from rain scavenging studies (e.g. Andronache et al., 2006; Wang et al., 2011; Quérel et al., 2013) can also be applied to snow scavenging. In addition, the upper-range values of the theoretical $\Lambda_{\text {snow }}$ formulas are believed to be more realistic and should be used in regional- to global-scale CTMs even though the upper range of the theoretical $\Lambda_{\text {snow }}$ values is still a factor of 2 or more smaller than empirical $\Lambda_{\text {snow }}$ values from field measurements. This recommendation reflects the competing facts that some processes such as turbulent diffusion that contribute to the higher measured values are already represented elsewhere in the CTMs, whereas some microphysical mechanisms relevant to rain scavenging such as thermophoresis, diffusiophoresis, and electrostatic forces are not accounted for in the theoretical $\Lambda_{\text {snow }}$ parameterizations.

\subsection{Impact of $\Lambda_{\text {snow }}$ uncertainties on predicted aerosol concentrations}

To investigate the impact of different $\Lambda_{\text {snow }}$ parameterizations on predicted aerosol-particle populations undergoing below-cloud snow scavenging, the same approach as that used in Wang et al. (2010) to investigate the impact of below-cloud rain scavenging was also used here. Briefly, the time evolution of a size-resolved aerosol-particle population can be obtained by solving Eq. (1) for any given $\Lambda_{\text {snow }}$. The bulk aerosol number and mass concentrations at any time $t$ can then be obtained from an integration by particle diameter over the entire aerosol-particle size distribution. For the cases discussed below, two snowfall intensities $\left(0.1 \mathrm{~mm} \mathrm{~h}^{-1}\right.$ and $1.0 \mathrm{~mm} \mathrm{~h}^{-1}$, as liquid water equivalent), three $\Lambda_{\text {snow }}$ parameterizations, and two initial aerosolparticle size distributions were chosen. The three $\Lambda_{\text {snow }}$ parameterizations considered were the $\mathrm{MP}+\mathrm{MH}+\mathrm{SL}$ formula, representing the lower range of the theoretical $\Lambda_{\text {snow }}$ parameterizations, the $\mathrm{SC}+\mathrm{MH}+\mathrm{MU}$ formula, representing the upper range of the theoretical $\Lambda_{\text {snow }}$ parameterizations, and the empirical formula developed by Paramonov et al. (2011) (see Figs. 7 and 8). The two initial aerosol size distributions correspond to a marine case and an urban case: the former represents the lower range of aerosol concentrations $\left(202 \mathrm{~cm}^{-3}\right.$ and $16.1 \mathrm{\mu g} \mathrm{m}^{-3}$ for initial number and mass concentrations, respectively) and the latter represents the upper range of aerosol concentrations $\left(1.37 \times 10^{5} \mathrm{~cm}^{-3}\right.$ and $101.7 \mathrm{~g} \mathrm{~m} \mathrm{~m}^{-3}$ for initial number and mass concentrations, respectively) (Wang et al., 2010). Equation (1) was then in- tegrated for each combination of snowfall intensity, $\Lambda_{\text {snow }}$ parameterization, and initial aerosol-particle size distribution with a time step of $10 \mathrm{~s}$ to the time when an accumulated total precipitation amount of $5 \mathrm{~mm}$ was reached.

Figure 9 shows the time evolution of the bulk number and mass concentrations normalized by their respective initial values. Significant differences in the predicted bulk number and mass concentrations were found from using different $\Lambda_{\text {snow }}$ formulas. In less than one hour for a typical snowfall intensity (e.g. $1.0 \mathrm{~mm} \mathrm{~h}^{-1}$ as liquid water equivalent, which is approximately $1 \mathrm{~cm} \mathrm{~h}^{-1}$ of accumulated snow depth; see second row in Fig. 9), factor-of-2 differences were found in both bulk number and mass concentrations for both marine and urban aerosol distributions. It is also clear from Fig. 9 that the impacts of using different $\Lambda_{\text {snow }}$ parameterizations are quantitatively different for the bulk number and mass concentrations. This is because $\Lambda_{\text {snow values are }}$ higher for large aerosol particles than for small ones and the bulk number concentration is associated with small particles, whereas the bulk mass concentration is generally associated with large particles, as can be seen from the initial particle size distributions shown in Fig. 10 in Wang et al. (2010). This explains why the bulk mass concentrations decreased more rapidly in the first hour than the bulk number concentrations, but the trend then reversed in later hours after the majority of larger particles had already been removed.

\subsection{Comparison between $\Lambda_{\text {snow }}$ and $\Lambda_{\text {rain }}$}

Comparing the uncertainties for $\Lambda_{\text {snow }}$ that have been reviewed in this study with those for $\Lambda_{\text {rain }}$ that were reviewed in a previous study (Wang et al., 2010), both similarities and differences were found in terms of the uncertainties caused by various input parameters. For both $\Lambda_{\text {snow }}$ and $\Lambda_{\text {rain }}$, the formulation of the collection efficiency $E$ between hydrometeors and aerosol particles is the largest source of uncertainty amongst all of the input parameters. The uncertainties in $\Lambda_{\text {snow }}$ and $\Lambda_{\text {rain }}$ caused by $E$ can be more than one order of magnitude for almost all aerosol-particle sizes. Uncertainties in $\Lambda_{\text {snow }}$ caused by other parameters (snow-particle number size spectrum, terminal velocity, and shape) can also be as large as one order of magnitude, whereas the corresponding uncertainties for $\Lambda_{\text {rain }}$ are all smaller than a factor of 5.0. The combined uncertainty from all sources is thus larger for $\Lambda_{\text {snow }}$ than for $\Lambda_{\text {rain }}$.

It has been speculated that snow particles might scavenge more aerosol particles (in terms of both number and mass concentrations) than raindrops do for an equivalent precipitation amount given the larger surface areas and various shapes of snow particles (Reiter and Carnuth, 1969; Magono et al., 1975; Graedel and Franey, 1975; Murakami et al., 1985; Sparmacher et al., 1993; Croft et al., 2009; Kyrö et al., 2009). A comparison of the empirical $\Lambda_{\text {snow }}$ formula of Kyrö et al. (2009) with the empirical $\Lambda_{\text {rain }}$ formula of Laakso et al. (2003) for a low precipitation intensity $\left(\sim 0.2 \mathrm{~mm} \mathrm{~h}^{-1}\right)$ 

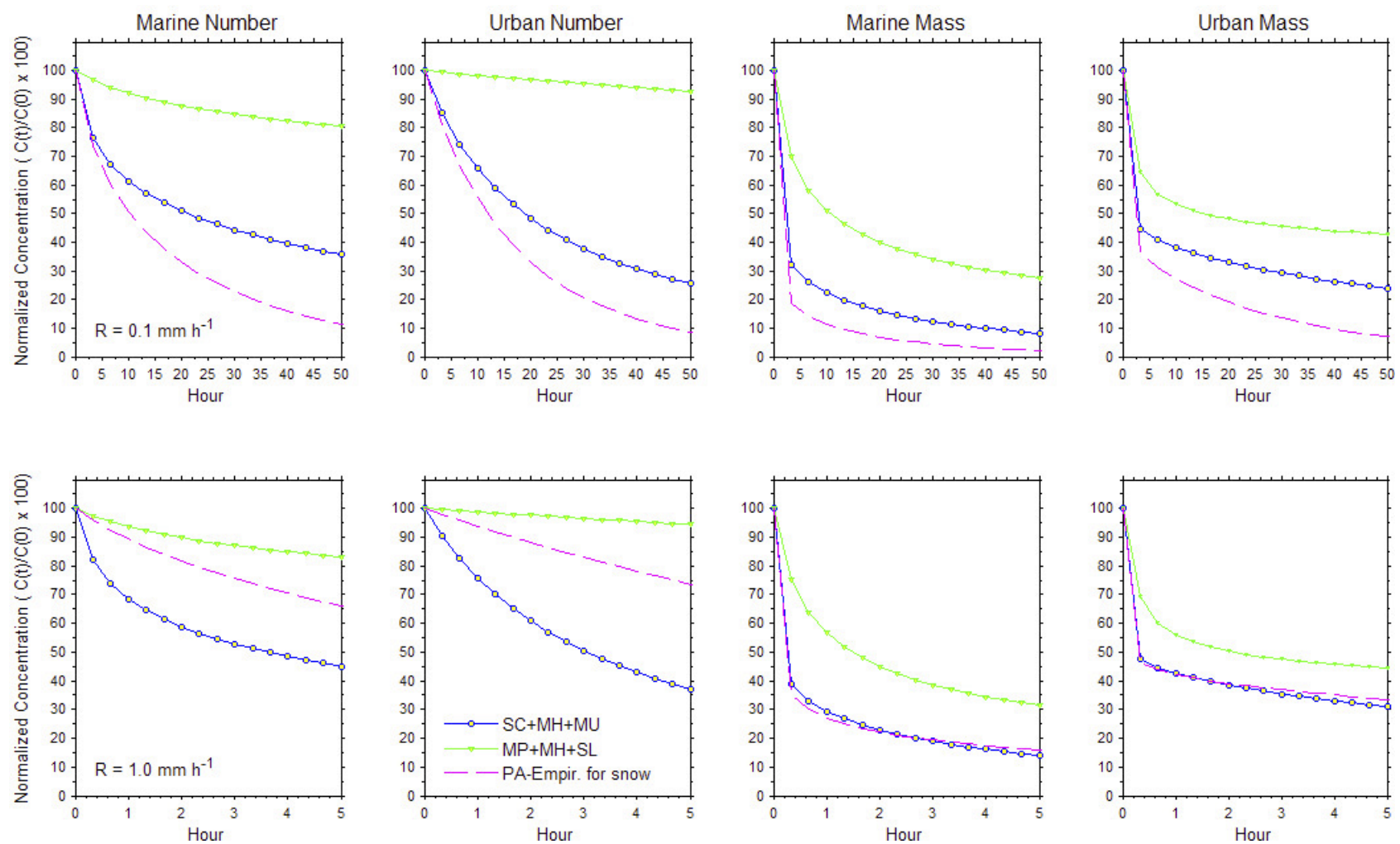

Fig. 9. Time evolution of normalized bulk aerosol number and mass concentrations for typical marine and urban aerosol populations under snow intensities of 0.1 and $1.0 \mathrm{~mm} \mathrm{~h}^{-1}$ (liquid water equivalent) calculated using two theoretical parameterizations and one empirical $\Lambda_{\text {snow }}$ parameterization shown in Figs. 7 and 8.

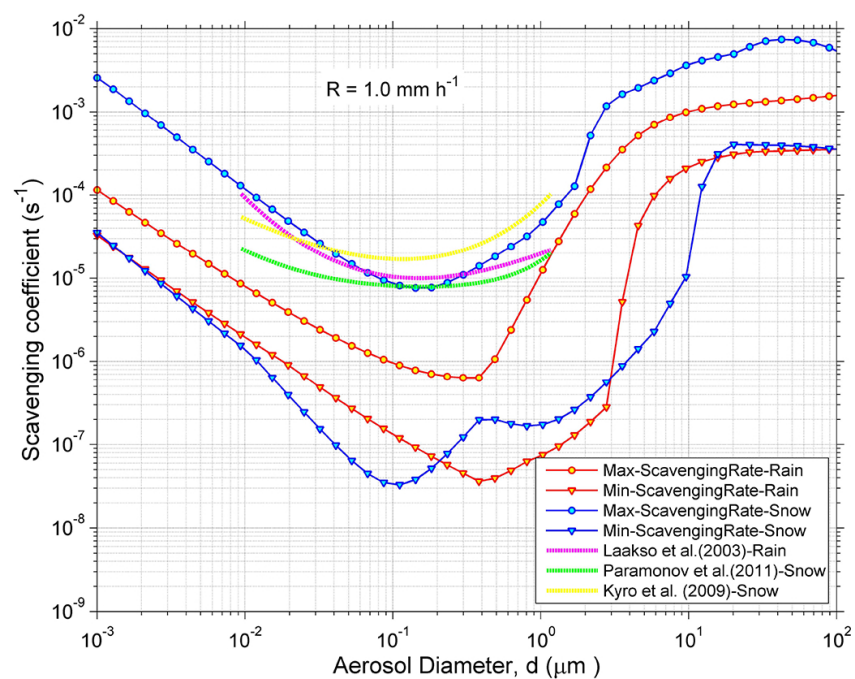

Fig. 10. The range of $\Lambda_{\text {snow }}$ generated from a combination of all four panels in Fig. 8 and the range of $\Lambda_{\text {rain }}$ from a review in Wang et al. (2010). Both pairs of curves represent the uncertainties in existing theoretical formulations. Also shown are curves for two empirical $\Lambda_{\text {snow }}$ parameterizations and one empirical $\Lambda_{\text {rain }}$ parameterization. also suggests that this is the case (Paramonov et al., 2011). To shed some light on this issue, one simple approach would be to compare directly the magnitude of $\Lambda_{\text {snow }}$ and $\Lambda_{\text {rain }}$ profiles generated for the same precipitation amounts. One challenge to this approach, though, is that both $\Lambda_{\text {snow }}$ and $\Lambda_{\text {rain }}$ have a large range of values and very large uncertainties.

A typical snowfall intensity (e.g. $1 \mathrm{~cm} \mathrm{~h}^{-1}$ of snow, which is approximately equivalent to $1 \mathrm{~mm} \mathrm{~h}^{-1}$ of liquid water) is chosen below as an example to compare the relative magnitudes of $\Lambda_{\text {snow }}$ and $\Lambda_{\text {rain }}$. The minimum and maximum $\Lambda_{\text {snow }}$ values (two blue lines) shown in Fig. 10 were extracted from all four panels of Fig. 8 in the present study (thus spanning the range of $\Lambda_{\text {snow }}$ values produced by the four habit types of snow crystals) while those for $\Lambda_{\text {rain }}$ (two red lines) were obtained from Fig. 8a of a previous study (Wang et al., 2010). $\Lambda_{\text {snow }}$ profiles from the empirical formulas of Kyrö et al. (2009) and Paramonov et al. (2011) (shown in Figs. 7 and 8), and a $\Lambda_{\text {rain }}$ profile from an empirical formula plotted in Fig. 8a of Wang et al. (2010) are also depicted in Fig. 10 (three dashed lines).

It can be seen in Fig. 10 that uncertainties in (or ranges of) $\Lambda_{\text {snow }}$ are up to two orders of magnitude for small $(<0.01 \mu \mathrm{m})$ and large aerosol particles $(>10 \mu \mathrm{m})$ and up to three orders of magnitude for median size aerosol particles. In comparison, uncertainties in $\Lambda_{\text {rain }}$ are smaller than one 
order of magnitude for small and large aerosol particles and mostly smaller than two orders of magnitude for median size aerosol particles; the only exception for rain is for aerosol particles of $1-3 \mu \mathrm{m}$, for which the uncertainties are slightly higher than two orders of magnitude. It should be pointed out that part of the large range of $\Lambda_{\text {snow }}$ values will be due to real variability (e.g. different snow-particle shapes and related properties affecting $\Lambda_{\text {snow }}$ ) while the other part will be due to parameterization errors (e.g. improper formulation of related parameters). The median and the upper range of $\Lambda_{\text {snow }}$ values are a factor of 5-10 higher than those of $\Lambda_{\text {rain }}$ values for most aerosol-particle sizes. As recommended above and also in Wang et al. (2010), the upper-range values of the theoretical $\Lambda_{\text {snow }}$ and $\Lambda_{\text {rain }}$ profiles, which are closer to, though still considerably smaller than, the field measurements, are thought to be more realistic. This suggests the possibility of faster removal of atmospheric aerosols by snow than by rain for an equivalent precipitation amount. However, almost all of the $\Lambda_{\text {rain }}$ values lie within the range of $\Lambda_{\text {snow }}$ values, which suggests that snow removal of aerosol particles may not always be faster than rain removal. The relative magnitudes of $\Lambda_{\text {snow }}$ and $\Lambda_{\text {rain }}$ should also depend on snow-particle shape (see the minimum $\Lambda_{\text {snow }}$ profiles in Fig. 8a and d) and on other conditions that may not be explicitly considered in either $\Lambda_{\text {snow }}$ or $\Lambda_{\text {rain }}$ (e.g. Wang et al., 2011; Paramonov et al., 2011).

Comparing the $\Lambda_{\text {snow }}$ and $\Lambda_{\text {rain }}$ profiles from the empirical formulas, it can be seen that the $\Lambda_{\text {rain }}$ profile is smaller than the $\Lambda_{\text {snow }}$ profile of Kyrö et al. (2009) but is larger than the $\Lambda_{\text {snow }}$ profile of Paramonov et al. (2011). It should be reiterated, however, that both $\Lambda_{\text {snow }}$ empirical formulas were based mostly on measurements associated with low snowfall intensities, but the $\Lambda_{\text {rain }}$ values in the figure were generated using a precipitation intensity of $1 \mathrm{~mm} \mathrm{~h}^{-1} . \Lambda_{\text {rain }}$ would be significantly smaller if a lower rainfall intensity had been used. Thus, it is likely that snow removal is more effective than rain removal in many situations, although this conclusion may not apply to all snow-particle shapes, to all aerosolparticle sizes, or under all other conditions. A firm conclusion thus cannot be drawn at this stage due to the limited number of field and laboratory studies that are available as well as the large uncertainties in the theoretical studies that have been quantified in this study and by Wang et al. (2010).

\section{Conclusions}

A review of current knowledge about $\Lambda_{\text {snow }}$, the sizeresolved scavenging coefficient for atmospheric aerosols scavenged below cloud by falling snow, was conducted in this study. The four component parameters needed for theoretical formulations of $\Lambda_{\text {snow }}$ all contribute significant uncertainties to the estimated $\Lambda_{\text {snow }}$ values. As expected, the formulation of the collection efficiency $E$ between snow particles and aerosol particles contributes the largest uncertainty to $\Lambda_{\text {snow }}$ amongst all of the component parameters. However, uncertainties caused individually by the other parameters were also up to one order of magnitude, which was unexpectedly large in contrast to values obtained in an uncertainty analysis for $\Lambda_{\text {rain }}$ presented in a previous study by Wang et al. (2010).

For a typical snowfall intensity of $1 \mathrm{~mm} \mathrm{~h}^{-1}$ (as liquid water equivalent, or approximately $1 \mathrm{~cm} \mathrm{~h}^{-1}$ of snow), the uncertainty associated with theoretically estimated $\Lambda_{\text {snow }}$ profiles spans nearly three orders of magnitude, in contrast to the one to two order-of-magnitude range for $\Lambda_{\text {rain }}$. Moreover, most $\Lambda_{\text {rain }}$ values lie in the lower end of the range of $\Lambda_{\text {snow }}$ values, which suggests that snow scavenging of atmospheric aerosol particles is likely more effective than rain scavenging in many cases for an equivalent precipitation intensity. However, under certain circumstances (e.g. aerosol-particle size, snow-particle shape, snowfall and rainfall intensity), removal by snow might be slower than removal by rain. A complete picture cannot be drawn at the present time due to our limited knowledge.

Because of the large range of estimated $\Lambda_{\text {snow }}$ and $\Lambda_{\text {rain }}$ values, simple semi-empirical formulas for size-resolved $\Lambda$ as a polynomial function of precipitation intensity might be appropriate for both $\Lambda_{\text {snow }}$ and $\Lambda_{\text {rain }}$. Such a new parameterization should not be based solely on field measurements because (1) they do not cover the whole size range of atmospheric aerosol particles, and (2) they implicitly include contributions from some additional processes that might already be included in regional- to global-scale chemical transport models. The new parameterization could be developed through curve fitting over a wide range of precipitation conditions using the full set of existing parameterizations and measurements reviewed in this and previous studies. The new parameterization should be more appropriate for use in regional- to global-scale CTMs than the existing theoretical formulas due to the avoidance of assumptions regarding the representativeness of component parameters $\left(E, V_{D}, A\right.$, $\left.N\left(D_{\mathrm{p}}\right)\right)$, although the uncertainties in $\Lambda$ might still be similar. Results from the development of such a parameterization will be published separately.

Lastly, all theoretical studies show that below-cloud scavenging of aerosol particles by snow particles depends on aerosol-particle size and snowfall intensity. Currently there are very few publications about measurement studies that investigated the influence of different aerosol-particle size distributions and snowfall intensities on below-cloud scavenging coefficients. Also, the size distribution and shapes of snow particles can be specific to specific synoptic systems. Hence, the undertaking and analysis of new observational experiments carried out in different climate regimes would be of much value to modellers, both for quantifying the contributions of different scavenging processes and for evaluating theoretical scavenging parameterizations. 


\section{Appendix A}

\section{$N\left(D_{\mathrm{p}}\right)$ from Scott (1982) (Table 2)}

Scott (1982) assumed the snow-particle number size distribution to follow the Marshall-Palmer (1948) distribution:

$N\left(D_{\mathrm{m}}\right)=N_{0 \mathrm{e}} \exp \left(-\beta_{\mathrm{e}} D_{\mathrm{m}}\right)$,

where $D_{\mathrm{m}}$ is the actual snow-particle size. In all of the calculations performed in this study, however, the equivalent diameter of the melted snow particles, $D_{\mathrm{p}}$, was used. It was thus necessary to convert $D_{\mathrm{m}}$ to $D_{\mathrm{p}}$ for the Scott (1982) distribution.

Mass is conserved when a snow particle melts:

$\rho_{\text {water }} \frac{\pi}{6} D_{\mathrm{p}}^{3}=\rho_{\text {ice }} \frac{\pi}{6} D_{\mathrm{m}}^{3}$.

Here $\rho_{\text {water }}=10^{6} \mathrm{~g} \mathrm{~m}^{-3}$, and the ice density (i.e. frozen density) for a snow particle was calculated from an empirical formula of Holroyd (1971):

$\rho_{\text {ice }}=\frac{170}{D_{\mathrm{m}}} \quad\left(\mathrm{g} \mathrm{m}^{-3}\right)$.

Combining Eqs. (A2) and (A3), we then obtain

$D_{\mathrm{m}}=\frac{10^{3}}{\sqrt{170}} D_{\mathrm{p}}^{3 / 2}$

$d D_{\mathrm{m}}=\frac{10^{6}}{170} \times \frac{3}{2} \times \frac{D_{\mathrm{p}}^{2}}{D_{\mathrm{m}}} d D_{\mathrm{p}} \quad(\mathrm{m})$.

The number of snow particles with a diameter from $D_{\mathrm{m}}$ to $D_{\mathrm{m}}+d D_{\mathrm{m}}$ in a unit volume of air, $N\left(D_{\mathrm{m}}\right) d D_{\mathrm{m}}$, can then be expressed as

$$
\begin{aligned}
N\left(D_{\mathrm{m}}\right) d D_{\mathrm{m}} & =N_{0 \mathrm{e}} \exp \left(-\beta_{\mathrm{e}} \frac{10^{3}}{\sqrt{170}} D_{\mathrm{p}}^{3 / 2}\right) \\
& \times \frac{10^{6}}{170} \times \frac{3}{2} \times \frac{D_{\mathrm{p}}^{2}}{D_{\mathrm{m}}} d D_{\mathrm{p}} \quad\left(\mathrm{m}^{-3}\right) .
\end{aligned}
$$

Here $N_{0 \mathrm{e}}=5.0 \times 10^{7}\left(\mathrm{~m}^{-4}\right), M=0.37 R^{0.94}\left(\mathrm{~g} \mathrm{~m}^{-3}\right)$, and $\beta_{\mathrm{e}}=2072 M^{-0.33}\left(\mathrm{~m}^{-1}\right)$.

\section{Appendix B}

\section{The empirical $\Lambda_{\text {snow }}$ formula from Kyrö et al. (2009)}

Kyrö et al. (2009) suggested a size-resolved $\Lambda_{\text {snow }}$ parameterization from an empirical fit to four years (2005-2008) of field measurements in a rural background environment in Finland:

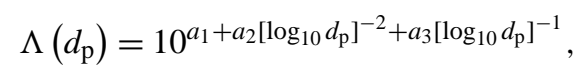

where $d_{\mathrm{p}}$ is particle diameter (in m), $a_{1}=22.7, a_{2}=1321.0$, and $a_{3}=381.0$. The parameterization applies to snowfall types of light continuous snowfall and snow grains with intensities of the order of $0.1 \mathrm{~mm} \mathrm{~h}^{-1}$ (as liquid water equiva-

\begin{tabular}{|c|c|}
\hline$a_{v}, b_{v}$ & empirical constants in $V_{D}$ power-law relationships \\
\hline$A$ & $\begin{array}{l}\text { snow-particle effective cross-sectional area } \\
\text { projected normal to the fall direction }\left(\mathrm{m}^{2}\right)\end{array}$ \\
\hline$d_{\mathrm{p}}$ & aerosol-particle diameter $(\mathrm{m})$ \\
\hline$D_{\mathrm{p}}$ & melted diameter of a snow particle (m) \\
\hline$D_{\mathrm{m}}$ & maximum dimension of a snow particle $(\mathrm{m})$ \\
\hline$D_{\mathrm{c}}$ & $\begin{array}{l}\text { snow-particle characteristic length used in } E \text { ex- } \\
\text { pression of Murakami et al. (1985) (m) }\end{array}$ \\
\hline$D_{\text {diff }}$ & aerosol-particle diffusivity coefficient $\left(\mathrm{m}^{2} \mathrm{~s}^{-1}\right)$ \\
\hline$E\left(d_{\mathrm{p}}, D_{\mathrm{p}}\right)$ & $\begin{array}{l}\text { snow particle-aerosol particle collection effi- } \\
\text { ciency }\end{array}$ \\
\hline$g$ & acceleration of gravity $\left(\mathrm{m} \mathrm{s}^{-2}\right)$ \\
\hline$M$ & precipitation water concentration $\left(\mathrm{g} \mathrm{m}^{-3}\right)$ \\
\hline$m$ & particle mass $(\mathrm{kg})$ \\
\hline$n\left(d_{\mathrm{p}}, t\right)$ & $\begin{array}{l}\text { aerosol number concentration with diameters } d_{\mathrm{p}} \\
\text { at time } t\end{array}$ \\
\hline$N_{0 \mathrm{e}}$ & $\begin{array}{l}\text { intercept parameter for exponential size } \\
\text { distribution }\left(\mathrm{m}^{-4}\right)\end{array}$ \\
\hline$N\left(D_{\mathrm{p}}\right)$ & snow-particle number size distribution $\left(\mathrm{m}^{-4}\right)$ \\
\hline$N_{\text {total }}$ & $\begin{array}{l}\text { total number concentration of snow particles } \\
\left(\mathrm{m}^{-3}\right)\end{array}$ \\
\hline $\mathrm{Pe}$ & Péclet number \\
\hline$R$ & precipitation intensity $\left(\mathrm{mm} \mathrm{h}^{-1}\right)$ \\
\hline $\operatorname{Re}$ & Reynolds number \\
\hline RH & relative humidity \\
\hline$S c$ & Schmidt number \\
\hline$S t$ & Stokes number \\
\hline$S t^{*}$ & critical Stokes number \\
\hline$v_{d}$ & aerosol-particle terminal velocity $\left(\mathrm{m} \mathrm{s}^{-1}\right)$ \\
\hline$V_{D}$ & snow-particle terminal velocity $\left(\mathrm{m} \mathrm{s}^{-1}\right)$ \\
\hline$X$ & Davies number \\
\hline$\alpha, \beta$ & $\begin{array}{l}\text { empirical constants in mass-diameter power-law } \\
\text { relationships }\end{array}$ \\
\hline$\beta_{\mathrm{e}}$ & slope parameter for exponential size distribution \\
\hline$\gamma, \sigma$ & $\begin{array}{l}\text { empirical constants in area-diameter power-law } \\
\text { relationships }\end{array}$ \\
\hline$\lambda$ & $\begin{array}{l}\text { snow-particle characteristic capture length used in } \\
E \text { expression of Slinn (1984) (m) }\end{array}$ \\
\hline$\Lambda\left(d_{\mathrm{p}}\right)$ & size-resolved scavenging coefficient $\left(\mathrm{s}^{-1}\right)$ \\
\hline$\mu_{\mathrm{a}}$ & dynamic air viscosity $\left(\mathrm{kg} \mathrm{m}^{-1} \mathrm{~s}^{-1}\right)$ \\
\hline$\rho_{\mathrm{a}}$ & air density $\left(\mathrm{kg} \mathrm{m}^{-3}\right)$ \\
\hline$\rho_{\text {water }}$ & water density $\left(\mathrm{kg} \mathrm{m}^{-3}\right)$ \\
\hline
\end{tabular}
lent) and to aerosol particles of $0.01-1.0 \mu \mathrm{m}$ in diameter.
Table A1. Nomenclature.

\section{Appendix C}

The empirical $\Lambda_{\text {snow }}$ formula from

Paramonov et al. (2011)

Paramonov et al. (2011) proposed a $\Lambda_{\text {snow }}$ parameterization from the empirical fit to field measurements from four winters (2006-2010) in an urban environment in Helsinki, Finland:

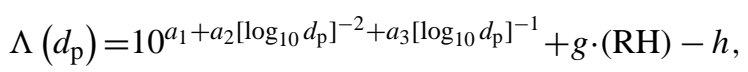


where $d_{\mathrm{p}}$ is particle diameter (in m) $a_{1}=28.0, a_{2}=1550.0$, $a_{3}=456.0, g=0.00015, h=0.00013$, and RH is relative humidity. The formula is only valid for aerosol particles of $0.01-1.0 \mu \mathrm{m}$ in diameter and snowfall intensities of 0.1 to $1.2 \mathrm{~mm} \mathrm{~h}^{-1}$ (as liquid water equivalent). Nevertheless, the formula is applicable to snowfall episodes of snowflakes, snow grains, snow crystals, ice pellets, as well as mixed with rain.

Acknowledgements. We greatly appreciate the three anonymous reviewers for providing the constructive comments which helped us to improve the paper.

Edited by: Y. Balkanski

\section{References}

Andronache, C., Grönholm, T., Laakso, L., Phillips, V., and Venäläinen, A.: Scavenging of ultrafine particles by rainfall at a boreal site: observations and model estimations, Atmos. Chem. Phys., 6, 4739-4754, doi:10.5194/acp-6-4739-2006, 2006.

Baklanov, A. and Sørensen, J. H.: Parameterisation of radionuclide deposition in atmospheric long-range transport modelling, Phys. Chem. Earth B, 26, 787-799, 2001.

Bell, D. A. and Saunders, C. P. R.: An experimental study of aerosol scavenging by hexagonal plate ice crystals, Atmos. Res., 38, 919, 1995.

Bohm, H. P.: A general equation for the terminal fall speed of solid hydrometeors, J. Atmos. Sci., 46, 2419-2427, 1989.

Bohm, H. P.: A general hydrodynamic theory for mixed-phase microphysics, Part I: Drag and fall speed of hydrometeors, Atmos. Res., 27, 253-274, 1992.

Chate, D. M.: Study of scavenging of submicron-sized aerosol particles by thunderstorm rain events, Atmos. Environ., 39, 66086619, 2005.

Cotton, W. R., Stephens, M. A., Nehrkorn, T., and Tripoli, G. J.: The Colorado State University three-dimensional cloud/mesoscale model, Part II: An ice phase parameterization, J. Rech. Atmos., 16, 295-319, 1982.

Croft, B., Lohmann, U., Martin, R. V., Stier, P., Wurzler, S., Feichter, J., Posselt, R., and Ferrachat, S.: Aerosol size-dependent below-cloud scavenging by rain and snow in the ECHAM5HAM, Atmos. Chem. Phys., 9, 4653-4675, doi:10.5194/acp-94653-2009, 2009.

Dick, A. L.: A simple model for air/snow fractionation of aerosol components over the Antarctic Peninsula, J. Atmos. Chem., 11, 179-196, 1990.

Feng, J.: A 3-mode parameterization of below-cloud scavenging of aerosols for use in atmospheric dispersion models, Atmos. Environ., 41, 6808-6822, 2007.

Feng, J.: A size-resolved model for below-cloud scavenging of aerosols by snowfalls, J. Geophys. Res., 114, D08203, doi:10.1029/2008JD011012, 2009.

Field, P. R. and Heymsfield, A. J.: Aggregation and scaling of ice crystal size distributions, J. Atmos. Sci., 60, 544-560, 2003.

Field, P. R., Hogan, R. J., Brown, P. R. A., Illingworth, A. J., Choularton, T. W., and Cotton, R. J.: Parameterization of ice- particle size distributions for mid-latitude stratiform cloud, Q. J. Roy. Meteor. Soc., 131, 1997-2017, 2005.

Flossman, A.: The scavenging of two different types of marine aerosol particles calculated using a two-dimensional detailed cloud model, Tellus, 43B, 301-321, 1991.

Gong, W., Dastoor, A. P., Bouchet, V. S., Gong, S. L., Makar, P. A., Moran, M. D., Pabla, B., Ménard, S., Crevier, L.-P., Cousineau, S., and Venkatesh, S.: Cloud processing of gases and aerosols in a regional air quality model (AURAMS), Atmos. Res., 82, 248275, 2006.

Gong, W., Stroud, C., and Zhang, L.: Cloud processing of gases and aerosols in air quality modeling, Atmosphere, 2, 567-616, doi:10.3390/atmos2040567, 2011.

Graedel, T. E. and Franey, J. P.: Field measurements of submicron aerosol washout by snow, Geophy. Res. Lett., 2, 325-328, 1975.

Gunn, K. L. S. and Marshall, J. S.: The distribution with size of aggregate snowflakes, J. Meteorol., 15, 452-461, 1958.

Harimaya, T., Kodama, H., and Muramoto, K.: Regional differences in snowflake size distributions, J. Meteorol. Soc. Jpn., 82, 895903, doi:10.2151/jmsj.2004.895, 2004.

Henzing, J. S., Olivié, D. J. L., and van Velthoven, P. F. J.: A parameterization of size resolved below cloud scavenging of aerosols by rain, Atmos. Chem. Phys., 6, 3363-3375, doi:10.5194/acp-63363-2006, 2006.

Heymsfield, A. J.: Properties of tropical and midlatitude ice cloud particle ensembles, Part I: Median mass diameters and terminal velocities, J. Atmos. Sci., 60, 2573-2591, 2003.

Hobbs, P. V., Radke, L. F., Locatelli, J. D., Atkinson, D. G., Robertson, C. E., Weiss, R. R., Turner, F. M., and Brown, R. R.: Research Report VII, Dep. of Atmos. Sci., University of Washington, Seattle, Washington, USA, 1972.

Holroyd, E. W.: The meso and microscale structure of Great Lakes snowstorm bands, Ph.D. Dissertation, State University of New York, Albany, New York, USA, 1971.

Houze Jr., R. A., Hobbs, P. V., Herzegh, P. H., and Parsons, A. D.: Size distributions of precipitation particles in front clouds, J. Atmos. Sci., 36, 156-162, 1979.

Jiusto, J. E. and Bosworth, G.: Fall velocity of snow flakes, J. Appl. Meteor., 10, 1352-1354, 1971.

Jylhä, K.: Relationship between the scavenging coefficient for pollutants in precipitation and the radar reflectivity factor, Part I: Derivation, J. Appl. Meteor., 38, 1421-1434, 1999.

Jylhä, K.: Removal by snowfall of emissions from a coal-fired power plant: observations and modelling, Water Air Soil Poll., 120, 397-420, 2000.

Knutson, E. D., Sood, S. K., and Stockham, J. J.: Aerosol collection by snow and ice crystals, Atmos. Environ., 10, 395-402, 1976.

Kyrö, E.-M., Grönholm, T., Vuollekoski, H., Virkkula, A., Kulmala, M., and Laakso, L.: Snow scavenging of ultrafine particles: Field measurements and parameterization, Boreal Environ. Res., 14, 527-538, 2009.

Laakso, L., Grönholm, T., Rannik, U., Kosmale, M., Fiedler, V., Vehkamäki, H., and Kulmala, M.: Ultrafine particle scavenging coefficients calculated from 6 years field measurements, Atmos. Environ., 37, 3605-3613, 2003.

Langleben, M. P.: The terminal velocity of snow aggregates, Q. J. Roy. Meteor. Soc., 80, 174-181, 1954. 
Lin, Y.-L., Farley, R. D., and Orville, H. D.: Bulk parameterization of the snow field in a cloud model, J. Clim. Appl. Meteorol., 22, 1065-1092, 1983.

Locatelli, J. D. and Hobbs, P. V.: Fall speeds and masses of solid precipitation particles, J. Geophys. Res., 79, 2185-2197, 1974.

Loosmore, G. A. and Cederwall, R. T.: Precipitation scavenging of atmospheric aerosols for emergency response applications: testing an updated model with new real-time data, Atmos. Environ., 38, 993-1003, 2004.

Magono, C., Endoh, T., and Itasaka, M.: Observation of aerosol particles attached to falling snow crystals, Journal of Faculty of Science of Hokkaido University, 4, 103-119, 1975.

Marshall, J. S. and Palmer, W. M.: The distribution of raindrop with size, J. Meteor., 5, 165-166, 1948.

Martin, J. J., Wang, P. K., and Pruppacher, H. R.: A theoretical determination of the efficiency with which aerosol particles are collected by simple ice crystal plates, J. Atmos. Sci., 37, 1628-1663, 1980.

Maryon, R. H., Smith, F. B., Conwy, B. J., and Goddard, D. M.: The UK nuclear accident response model (NAME), Prog. Nucl. Energy, 26, 85-104, 1992.

Matson, R. J. and Huggins, A. W.: The direct measurement of sizes, shapes and kinematics of falling hailstones, J. Atmos. Sci., 37, 1107-1125, 1980.

Miller, N. L. and Wang, P. K.: Theoretical determination of the efficiency of aerosol particle collection by falling columnar ice crystals, J. Atmos. Sci., 46, 1656-1663, 1989.

Mitchell, D. L.: Evolution of snow-size spectra in cyclonic storms, Part II: deviations from the exponential form, J. Atmos. Sci, 45, 3431-3451, 1991.

Mitchell, D. L.: Use of mass- and area-dimensional power laws for determining precipitation particle terminal velocities, J. Atmos. Sci., 53, 1710-1723, 1996.

Mitchell, D. L. and Arnott, W. P.: A model predicting the evolution of ice particle size spectra and the radiative properties of cirrus clouds, Part II: Dependencies of absorption and extinction on ice crystal morphology, J. Atmos. Sci., 51, 817-832, 1994.

Mitchell, D. L. and Heymsfield, A. J.: Refinements in the treatment of ice particle terminal velocities, highlighting aggregates, J. Atmos. Sci., 62, 1637-1644, 2005.

Mitchell, D. L., Zhang, R., and Pitter, R. L.: Mass-dimensional relationships for ice particles and the influence of riming on snowfall rates, J. Appl. Meteor., 29, 153-163, 1990.

Molthan, A. L., Petersen, W. A., Nesbitt, S. W., and Hudak, D.: Evaluating the snow crystal size distribution and density assumptions within a single-moment microphysics scheme, Mon. Weather Rev., 138, 4254-4267, 2010.

Morrison, G., Thompson, G., and Tatarskii, V.: Impact of cloud microphysics on the development of trailing stratiform precipitation in a simulated squall line: Comparison of one- and two-moment schemes, Mon. Weather Rev., 137, 991-1007, 2009.

Murakami, M., Magono, C., and Kikuchi, K.: Experiments on aerosol scavenging by natural snow crystals, Part III: The effect of snow crystal charge on collection efficiency, J. Meteorol. Soc. Jpn., 63, 1127-1137, 1985.

Paramonov, M., Grönholm, T., and Virkkula, A.: Below-cloud scavenging of aerosol particles by snow at an urban site in Finland, Boreal Environ. Res., 16, 304-320, 2011.
Passarelli, R. E.: Theoretical and observational study of snow-size spectra and snowflake aggregation efficiencies, J. Atmos. Sci., 35, 882-889, 1978.

Pruppacher, H. R. and Klett, J. D.: Microphysics of clouds and precipitation, Kluwer Academic Publishers, Dordrecht, 954 pp., 1997.

Quérel, A., Monier, M., Flossmann, A. I., Lemaitre, P., and Porcheron, E.: The importance of new collection efficiency values including the effect of rear capture for the below-cloud scavenging of aerosol particles, Atmos. Res., doi:10.1016/j.atmosres.2013.06.008, in press, 2013.

Ranz, W. E. and Wong, J. B.: Impaction of dust and smoke particles, Ind. Eng. Chem., 44, 1371-1381, doi:10.1021/ie50510a050, 1952.

Rasch, P. J., Feichter, J., Law, K., Mahowald, N., Penner, J., Benkovitz, C., Genthon, C., Giannakopoulos, C., Kasibhatla, P., Koch, D., Levy, H., Maki, T., Prather, M., Roberts, D. L., Roelofs, G.-J., Stevenson, D., Stockwell, Z., Taguchi, S., Kritz, M., Chipperfield, M., Baldocchi, D., McMurry, P., Barrie, L., Balkanski, Y., Chatfield, R., Kjellstrom, E., Lawrence, M., Lee, H. N., Lelieveld, J., Noone, K. J., Seinfeld, J., Stenchikov, G., Schwartz, S., Walcek, C., and Williamson, D.: A comparison of scavenging and deposition processes in global models: Results from the WCRP Cambridge Workshop of 1995, Tellus, 52B, 1025-1056, 2000.

Reisner, J., Rasmussen, R. M., and Bruintjes, R. T.: Explicit forecasting of supercooled liquid water in winter storms using the MM5 forecast model, Q. J. Roy. Meteor. Soc., 124, 1071-1107, 1998.

Reiter, R. and Carnuth, W.: Washout-Untersuchungen an FalloutPartikeln in der unteren Troposphäre zwischen 700 und $3000 \mathrm{~m}$ NN, Arch. Meteor. Geophys. Bioklim., Series A, 18, 111-146, 1969.

Rotstayn, L. D. and Lohmann, U.: Simulation of the tropospheric sulfur cycle in a global model with a physically based cloud scheme, J. Geophys. Res., 107, 4592, doi:10.1029/2002JD002128, 2002.

Rutledge, S. A. and Hobbs, P. V.: The mesoscale and microscale structure and organization of clouds and precipitation in midlatitude cyclones, Part VIII: A model for the "seeder-feeder" process in warm-frontal rainbands, J. Atmos. Sci., 40, 1185-1206, 1983.

Santachiara, G., Prodi, F., and Belosi, F.: A review of thermo- and diffusio-phoresis in the atmospheric aerosol scavenging process. Part 1: Drop scavenging, Atmospheric and Climate Sciences, 2, 148-158, 2012.

Sauter, D. P. and Wang, P. K.: An experimental study of the scavenging of aerosol particles by natural snow crystals, J. Atmos. Sci., 46, 1650-1655, 1989.

Scott, B. C.: Theoretical estimates of the scavenging coefficient for soluble aerosol particles as a function of precipitation type, rate and altitude, Atmos. Environ., 16, 1753-1762, 1982.

Seinfeld, J. H. and Pandis, S. N.: Atmospheric chemistry and physics: from air pollution to climate change, Wiley \& Sons, New Jersey, 1203 pp., 2006.

Sekhon, K. S. and Srivastava, R. C.: Snow size spectra and radar reflectivity, J. Atmos. Sci., 27, 299-307, 1970.

Slinn, W. G. N.: Precipitation scavenging, in: Atmospheric Science and Power Production, Chap. 11, edited by: Randerson, D., No. 
DOE/TIC-27601, US Department of Energy, Washington, DC, 466-532, 1984.

Smith, P. L.: Equivalent radar reflectivity factors for snow and ice particles, J. Clim. Appl. Meteorol., 23, 1258-1260, 1984.

Sofiev, M., Siljamo, P., Valkama, I., Ilvonen, M., and Kukkonen, J.: A dispersion modelling system SILAM and its evaluation against ETEX data, Atmos. Environ., 40, 674-685, doi:10.1016/j.atmosenv.2005.09.069, 2006.

Solomon, A., Morrison, H., Persson, O., Shupe, M. D., and Bao, J. W.: Investigation of microphysical parameterizations of snow and ice in Arctic clouds during M-PACE through modelobservation comparisons, Mon. Weather Rev., 137, 3110-3128, 2009.

Sparmacher, H., Fulber, K., and Bonka, H.: Below-cloud scavenging of aerosol particles: Particle-bound radionuclides - Experimental, Atmos. Environ., 27A, 605-618, 1993.

Sportisse, B.: A review of parameterizations for modelling dry deposition and scavenging of radionuclides, Atmos. Environ., 41, 2683-2698, 2007.

Starr, D. O. and Cox, S. K.: Cirrus clouds, Part I: A cirrus cloud model, J. Atmos. Sci., 42, 2663-2681, 1985.

Textor, C., Schulz, M., Guibert, S., Kinne, S., Balkanski, Y., Bauer, S., Berntsen, T., Berglen, T., Boucher, O., Chin, M., Dentener, F., Diehl, T., Easter, R., Feichter, H., Fillmore, D., Ghan, S., Ginoux, P., Gong, S., Grini, A., Hendricks, J., Horowitz, L., Huang, P., Isaksen, I., Iversen, I., Kloster, S., Koch, D., Kirkevåg, A., Kristjansson, J. E., Krol, M., Lauer, A., Lamarque, J. F., Liu, X., Montanaro, V., Myhre, G., Penner, J., Pitari, G., Reddy, S., Seland, Ø., Stier, P., Takemura, T., and Tie, X.: Analysis and quantification of the diversities of aerosol life cycles within AeroCom, Atmos. Chem. Phys., 6, 1777-1813, doi:10.5194/acp-6-1777-2006, 2006.

Thompson, G., Rasmussen, R. M., and Manning, K.: Explicit forecasts of winter precipitation using an improved bulk microphysics scheme., Part I: Description and sensitivity analysis, Mon. Weather Rev., 132, 519-542, 2004.
Thompson, G., Field, P. R., Rasmussen, R. M., and Hall, W. D.: Explicit forecasts of winter precipitation using an improved bulk microphysics scheme, Part II: Implementation of a new snow parameterization, Mon. Weather Rev., 136, 5095-5115, 2008.

Tinsley, B. A., Rohrbaugh, R. P., Hei, M., and Beard, K. V.: Effects of image charges on the scavenging of aerosol particles by cloud droplets and on droplet charging and possible ice nucleation processes, J. Atmos. Sci., 57, 2118-2134, 189-205, 2000.

Tost, H., Jöckel, P., Kerkweg, A., Sander, R., and Lelieveld, J.: Technical note: A new comprehensive SCAVenging submodel for global atmospheric chemistry modelling, Atmos. Chem. Phys., 6, 565-574, doi:10.5194/acp-6-565-2006, 2006.

Wang, X., Zhang, L., and Moran, M. D.: Uncertainty assessment of current size-resolved parameterizations for below-cloud particle scavenging by rain, Atmos. Chem. Phys., 10, 5685-5705, doi:10.5194/acp-10-5685-2010, 2010.

Wang, X., Zhang, L., and Moran, M. D.: On the discrepancies between theoretical and measured below-cloud particle scavenging coefficients for rain - a numerical investigation using a detailed one-dimensional cloud microphysics model, Atmos. Chem. Phys., 11, 11859-11866, doi:10.5194/acp-11-11859-2011, 2011.

Woods, C. P., Stoelinga, M. T., and Locatelli, J. D.: Size spectra of snow particles measured in wintertime precipitation in the Pacific Northwest, J. Atmos. Sci., 65, 189-205, doi:10.1175/2007JAS2243.1, 2008.

Zhang, L., Michelangeli, D. V., and Taylor, P. A.: Numerical studies of aerosol scavenging in low-level, warm stratiform clouds and precipitation, Atmos. Environ., 38, 4653-4665, 2004.

Zhang, Y.: Online-coupled meteorology and chemistry models: history, current status, and outlook, Atmos. Chem. Phys., 8, 2895 2932, doi:10.5194/acp-8-2895-2008, 2008. 